\title{
Evolution of Size and Chemical Composition of Copper Concentrate Particles Oxidized Under Simulated Flash Smelting Conditions
}

\author{
MANUEL PÉREZ-TELLO, VÍCTOR R. PARRA-SÁNCHEZ, \\ VÍCTOR M. SÁNCHEZ-CORRALES, AGUSTÍN GÓMEZ-ÁLVAREZ, \\ FRANCISCO BROWN-BOJÓRQUEZ, ROBERTO A. PARRA-FIGUEROA, \\ EDUARDO R. BALLADARES-VARELA, and EUGENIA A. ARANEDA-HERNÁNDEZ
}

\begin{abstract}
An experimental study was conducted to elucidate the evolution of size and chemical composition of La Caridad copper concentrate particles during oxidation under simulated flash smelting conditions. Input variables tested included particle size and oxygen concentration in the process gas. The response variables included the size distributions, chemical composition, and morphology of the reacted particles at seven locations along a laboratory reactor. Particles with initial size $<45 \mu \mathrm{m}$ contained mostly chalcopyrite, they increased their mean size and decreased the amount of dust in the population during oxidation. This was explained by a reaction path involving rapid melting followed by collision and coalescence of reacting droplets during flight. Particles with sizes $>45 \mu \mathrm{m}$ contained varying amounts of chalcopyrite and pyrite, and tended to either maintain or decrease their mean size upon oxidation. When size reduction was observed, dust was produced because of fragmentation, and the particles showed no evidence of collisions during flight. The main oxidation products detected in the particles consisted of matte, cuprospinel, and magnetite. A plot of the mean size divided by the mean size in the feed against the fraction of sulfur eliminated generalized the experimental data so far reported in the literature, and helped identify the reaction path followed by the particles.
\end{abstract}

https://doi.org/10.1007/s11663-018-1183-1

(c) The Minerals, Metals \& Materials Society and ASM International 2018

\section{INTRODUCTION}

SINCE its commercial implementation in the past century, ${ }^{[1]}$ the flash smelting process of copper concentrates has been the subject of continued research. This is because a number of phenomena occurring in the reaction shaft of the process are yet not well understood. ${ }^{[2]}$ The elucidation of the fundamental aspects governing the behavior of the flash smelting reactor may help optimize its operation in terms of energy requirements, the quality of the molten products obtained, and

MANUEL PÉREZ-TELLO, VÍCTOR R. PARRA-SÁNCHEZ, VÍCTOR M. SÁNCHEZ-CORRALES, and AGUSTÍN GÓMEZÁLVAREZ are with the Department of Chemical Engineering and Metallurgy, University of Sonora, Blvd. Luis Encinas \& Rosales, Hermosillo 83000, Mexico. Contact e-mail: mperezt@iq.uson.mx FRANCISCO BROWN-BOJÓRQUEZ is with the Department of Polymers and Materials, University of Sonora. ROBERTO A. PARRA-FIGUEROA, EDUARDO R. BALLADARES-VARELA, and EUGENIA A. ARANEDA-HERNÁNDEZ are with the Department of Metallurgical Engineering, University of Concepción, Concepción 4070386, Chile.

Manuscript submitted September 7, 2017.

Article published online January 31, 2018. its potential impact on the environment, among other issues. Over the last decades, extensive experimentation has been conducted on the flash smelting ${ }^{[3-17]}$ and flash converting ${ }^{[18-21]}$ processes by means of stagnant- and laminar-flow reactors. As a result, the reaction path originally proposed by Kim and Themelis ${ }^{[10]}$ and further modified by Jokilaakso et al. ${ }^{[11]}$ and Yli-Pentila et al. ${ }^{[20]}$ has been widely accepted as a descriptive model which explains most of the experimental observations made under controlled laboratory conditions. The model is shown schematically in Figure 1 and is discussed in detail in the literature, ${ }^{[11,20,21]}$ thus only a brief description is provided here. Upon entering the reactor, the initial particles are first heated up by the gas phase by interphase heat transfer and the reactor walls by radiation. The oxidation starts at the particle surface, forming a porous shell of oxides surrounding the unreacted core of sulfides. Because the oxidation reactions are highly exothermic, particle temperature increases rapidly until eventually the melting point of the sulfides is reached. Under such conditions, the sulfur dioxide gas produced by the oxidation accumulates within the molten core and increases the internal pressure in the particle. The gas then pushes the oxide 
shell out causing particle bloating. When the internal pressure overcomes the resistance of the oxide shell, the particle undergoes fragmentation at an extent which depends on the local conditions in the reactor.

An alternative path is possible when the heating rate of the initial particle is so high that it becomes fully molten before any significant oxidation occurred in the particle. In such a case, the initial droplet may disintegrate violently, possibly due to pyritic decompositions that release gas. This produces many small droplets which further undergo oxidation. The reaction path shown in Figure 1 assumes that the particle-gas suspension is very dilute, and thus particle-particle collisions during flight are negligible. So far, few studies have addressed the size changes experienced by copper concentrate particles during oxidation under flash smelting conditions. The first documented work on this subject was due to Jorgensen ${ }^{[9]}$ who measured the size distribution of chalcopyrite concentrate particles in a laboratory reactor by an image analysis technique. Under $973 \mathrm{~K}$ and air atmosphere, the author found that the final mean size was about $40 \mu \mathrm{m}$, regardless of the initial size of the particles. Overall, the smallest sieved fraction $<37 \mu \mathrm{m}$ maintained its mean size, whereas sieved fractions of larger sizes tended to decrease their mean size upon oxidation. Jokilaakso et $a l^{[11]}$ conducted oxidation experiments with four sieved fractions of chalcopyrite concentrate particles (28 to 38 up to 62 to $74 \mu \mathrm{m}$ ). Because the amount of sample collected during the oxidation tests was small, the measurement of the size distribution of the reacted particles was not possible. However, scanning electron microscopy (SEM) images of the samples showed that

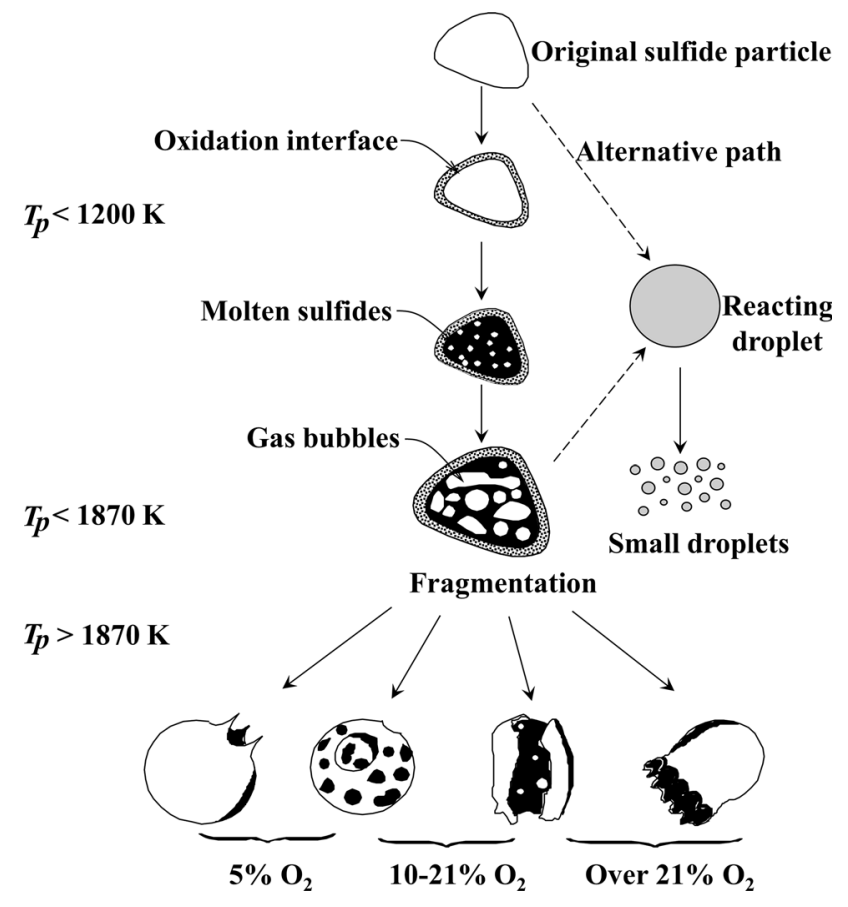

Fig. 1-Reaction path of sulfide particles during flash smelting under conditions of low density of the particle-gas suspension. Adapted from Refs. [11] and [21]. the finest fraction 28 to $38 \mu \mathrm{m}$ fairly retained its original size, whereas the coarser fractions underwent extensive fragmentation. For particles oxidized at $973 \mathrm{~K}$, the mean size estimated by the authors by inspection of the SEM images was in the range of 30 to $60 \mu \mathrm{m}$, which agreed well with previous observations by Jorgensen. ${ }^{[9]}$ Hagni et $a .^{[22]}$ reported on a mineralogical study of copper concentrate particles oxidized under suspended-smelting conditions in a large laboratory reactor. The authors noted that the size of the initial particles varied in the range of 20 to $50 \mu \mathrm{m}$, whereas the reacted particles were mostly in the range of 50 to $100 \mu \mathrm{m}$, i.e., particles significantly larger than those in the feed were observed. The morphology of most reacted particles was spherical. Pérez-Tello et al. ${ }^{[21]}$ reported on oxidation experiments with high-grade copper matte particles $(72 \mathrm{pct} \mathrm{Cu})$ in a large laboratory furnace. The authors found that the finest particles in the feed $(<37 \mu \mathrm{m})$ tended to increase their mean size upon oxidation and decrease the amount of particles with sizes less than $20 \mu \mathrm{m}$. Such results differed significantly from the behavior of other sieved fractions, which decreased their mean size upon oxidation with substantial generation of dust. Stefanova and Trifono $^{[23]}$ measured the size distributions of chalcopyrite particles before and after oxidation by means of a centrifugal particle size analyzer. They noted that the sizes of the initial particles ( 5 to $80 \mu \mathrm{m}$ ) extended to 5 to $95 \mu \mathrm{m}$. Particles within the size range of 35 to $65 \mu \mathrm{m}$, which were dominant in the initial population, decreased substantially upon oxidation, whereas particles of about $5 \mu \mathrm{m}$ increased in the reacted products. The authors attributed such observations to fragmentation of the initial particles due to thermal shock and dissociation. On the other hand, new particles larger than $80 \mu \mathrm{m}$ appeared in the reacted products. The authors suggested that collisions and fusion of hot droplets during flight were mostly responsible for such size increase. Vaarno et al. ${ }^{[24]}$ used two-wavelength pyrometry techniques to conduct simultaneous measurements of size and temperature of copper concentrate particles as they underwent oxidation in a laminar-flow reactor. Their graphical results indicated that both fine particles as well as particles larger than those in the feed were produced in the reactor as the oxygen concentration in the process gas was increased.

Whereas the previous studies pointed out the relevance of the initial size on the particle oxidation behavior, it is expected that particle mineralogy also plays a significant role on such transformations, as it determines the particle reaction path. Regarding plant operation data, Kimura et al. ${ }^{[25]}$ and Kemori et al. ${ }^{[26]}$ collected samples at several positions along the reaction shaft of a pilot-scale flash smelting reactor. The authors found that both the mean size and the amount of sulfur eliminated from the particles increased along the reaction shaft. The authors proposed a reaction path which involves the partial oxidation and collision of molten and solid particles during flight. Whereas such results were in discrepancy with the general observations made under laboratory conditions at the time,$^{[3,6,9,10]}$ Themelis et $a l^{[27]}$ further proposed that both fragmentation and 
collision followed by agglomeration of particles may occur depending on the local values of particle number density and turbulent intensity in the industrial reactor. However, the authors did not report on the details of their calculations and the order of magnitude of both quantities. Higgins et al. ${ }^{[28]}$ developed an axisymmetric mathematical model of particle agglomeration in the reaction shaft of a flash smelting reactor. The model assumed that collisions occur between pairs of particles with a rate which depends on the turbulent kinetic energy of the particle-gas suspension as well as the sizes, local number densities, and local velocities of the colliding particles. The efficiency of such collisions to produce new agglomerates was assumed to be dependent on the particle temperature. The model predictions showed fair agreement with the experimental trends observed by Kimura et al. ${ }^{[25]}$ and Kemori et al ${ }^{[26]}$ in a pilot-scale facility.

With the exception of the works by Jorgensen, ${ }^{[9]}$ Kimura et al., ${ }^{[25]}$ and Kemori et al., ${ }^{[26]}$ the abovementioned studies have addressed the size changes experienced by the particles as secondary responses of otherwise kinetic studies in which the major focus was the chemical and morphological transformations experienced by the particles. The experimental measurement of the size changes along the trajectory of the particle population is relevant because it may provide additional clues on the reaction path followed by the particles during flight. It may also provide experimental data to validate fundamentally based mathematical models of agglomeration $^{[28]}$ and fragmentation ${ }^{[29]}$ phenomena. Based on preliminary tests on this matter conducted in this laboratory, ${ }^{[30,31]}$ the goal of this investigation was twofold. First, to determine the evolution of size distributions, mean size, and amount of dust in a population of copper concentrate particles as they undergo oxidation under simulated flash smelting conditions. And second, to correlate such responses with the chemical transformations experienced by the particles and with experimental data reported in the literature. $^{[9,26]}$ To accomplish this goal, an experimental program was followed as described below.

\section{EXPERIMENTAL WORK}

Figure 2 shows the experimental setup used in this study. The system consists of a solid feed assembly (SFA), a gas feed unit, a reaction shaft, a product receptacle, and a gas-cleaning unit. The SFA consists of a vibratory feeder and a stainless steel, water-cooled lance resting on a flat metallic platform. The SFA was aligned with the reaction shaft by bolts which attached the metallic platform to a large metallic structure (not shown) supporting the whole experimental setup. The lance was detachable, and was adjusted to the metallic platform by a ring-shaped tightening device. The lance entered the furnace through the center $0.035 \mathrm{~m}$ diameter opening of the water-cooled burner. The lance inner diameter was $0.02 \mathrm{~m}$ and was used as the primary stream for the particles. For that purpose, a stainless steel funnel was placed on top of the lance to direct the particles coming from the vibratory feeder towards the reaction chamber. The SFA was moved vertically by a system of pulleys and wires not shown in Figure 2. The vertical position of the SFA relative to the furnace roof determined the length that the lance penetrated the furnace, and thus the residence time of the particles in the reaction chamber. The process gas was supplied by two rotameters handling pure oxygen and nitrogen, respectively, at room pressure and temperature (100.9 kPa, $298 \mathrm{~K}$ in Hermosillo, Mexico). The process gas entered the reaction chamber through a $1 \mathrm{~mm}$-width annulus built inside the burner which provided a uniform gas distribution to the reactor.

The reaction shaft was a vertical, 1-piece cast alumina ceramic cylinder. Its inner diameter was $0.105 \mathrm{~m}$, length $0.91 \mathrm{~m}$, and wall thickness $0.02 \mathrm{~m}$. The reaction chamber was heated up by two electrical resistances embedded within the ceramic cylinder and connected in parallel. Six K-type thermocouples were placed along the outer wall of the reactor and interfaced to a portable computer through a data logger. The thermocouple readings were used to monitor the temperature of the reaction shaft and provided the input to the temperature controller. The ceramic cylinder was surrounded by a compact $0.1-\mathrm{m}$-thick layer of ceramic fiber acting as thermal insulator. The whole assembly was enclosed within a metallic $0.35 \mathrm{~m}$ diameter, $1.1 \mathrm{~m}$ length cylindrical shell bolted to the large supporting structure. The bottom of the reaction chamber was attached to a stainless steel water-cooled receptacle. The lower portion of the receptacle was detachable and fixed to the shaft body by bolts. The goal of the receptacle was to quench the particles falling from the reaction shaft, thus interrupting the oxidation reactions, and collect them for further analysis. The upper portion of the receptacle had a side stream $0.025 \mathrm{~m}$ diameter opening for the exhaust gas. The off-gas was taken out of the reactor by means of a vacuum pump and bubbled into a $20 \mathrm{~L}$ plastic vessel containing 1.6 $\mathrm{M} \mathrm{NaOH}$ aqueous solution for the absorption of the sulfur dioxide gas produced by the oxidation reactions.

In this study, La Caridad copper concentrate provided by Mexicana de Cobre, S.A. was used as the raw material. The concentrate was wet-sieved in small batches for $20 \mathrm{~min}$ and separated into the target size fractions: $<45,45$ to 53,53 to 74,74 to 106,106 to 149 , and $>149 \mu \mathrm{m}$. Prior to the experiments, all sieved fractions and the original concentrate were dried in batches of $25 \mathrm{~kg}$ in a laboratory oven at $378 \mathrm{~K}$ for 24 hours and its moisture content was determined by thermogravimetric analysis in a Thermal Analysis SDT 2960 unit. In all cases, the moisture content was found to be less than 1 pet by weight, which was suitable for the oxidation tests. The dried particles were further labeled and stored in sealed plastic bags. Representative samples of the dried particles were chemically analyzed by atomic absorption spectroscopy (AAS) in a PerkinElmer AAnalyst 400 unit to determine copper and iron contents. The amounts of sulfur and silicon in the particles were determined gravimetrically. For comparison purposes, an alternative analysis was conducted by means of a quantitative evaluation of minerals by 


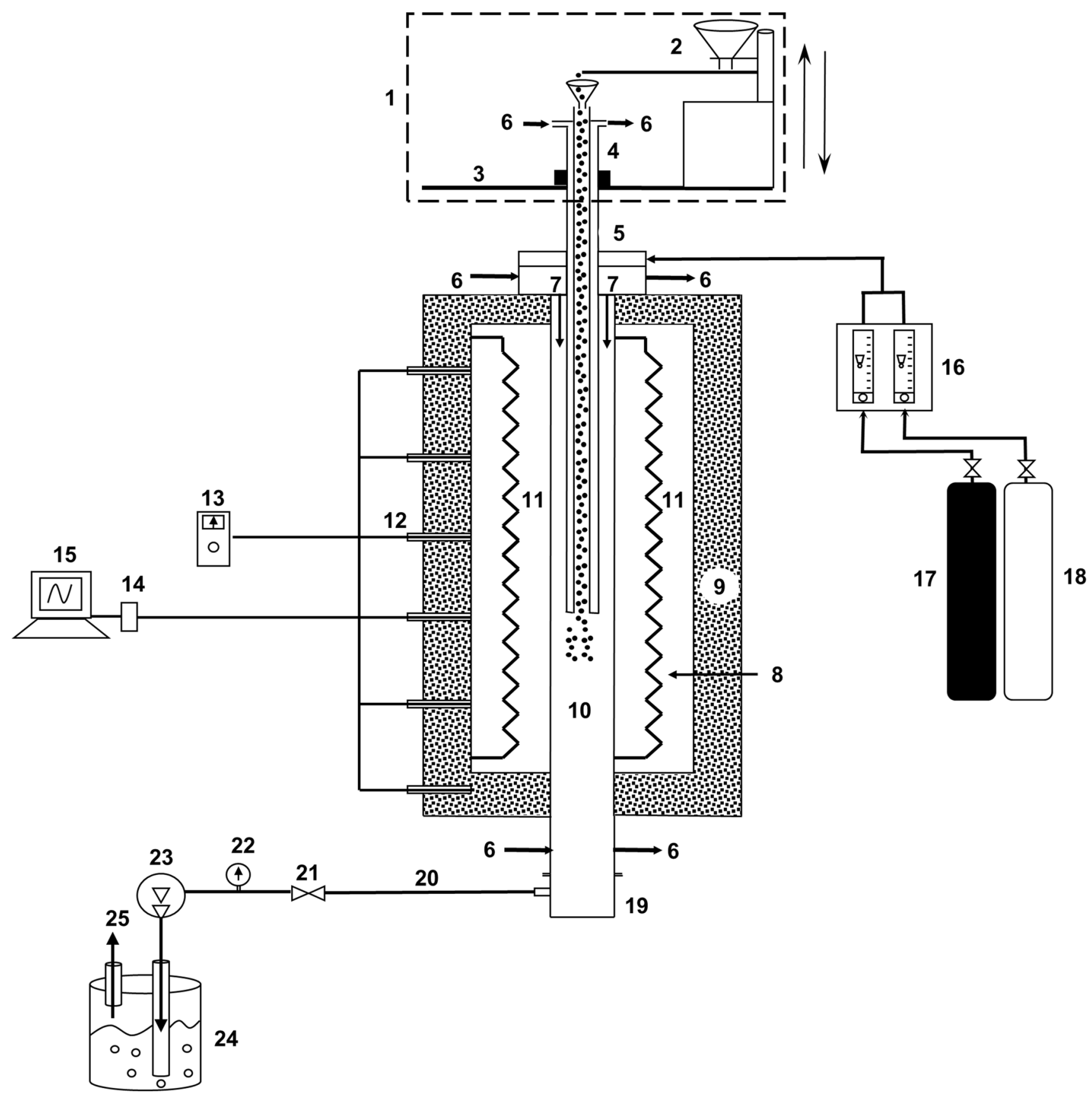

Fig. 2-Schematic representation of the laboratory reactor used for the oxidation tests; (1) solid feed assembly; (2) vibratory feeder; (3) metallic platform; (4) water-cooled lance; (5) burner; (6) cooling water; (7) gas inlet; (8) ceramic cylinder; (9) thermal insulator; (10) reaction chamber; (11) electrical resistance; (12) thermocouples; (13) temperature controller; (14) data logger; (15) portable computer; (16) rotameters; (17) oxygen cylinder; (18) nitrogen cylinder; (19) receptacle; (20) exhaust gas line; (21) valve; (22) manometer; (23) vacuum pump; (24) gas-cleaning vessel; (25) gas vent. Reprinted with permission from Instituto de Ingenieros de Minas de Chile (IIMCh). ${ }^{[30,31]}$

scanning electron microscopy $\left(\text { QEMSCAN }{ }^{*}\right)^{[32]}$ using

*QEMSCAN ${ }^{*}$ is a trademark of FEI Company, Hillsboro, Oregon, U.S.A.

a Tescan-Vega system model LSH with four energy-dispersive X-ray spectroscopy (EDS) detectors. Particle mineralogy was determined by X-ray diffraction (XRD) techniques in a Bruker D4 Endeavor diffractometer. The identification of the XRD results was made with the Match! software. ${ }^{[33]}$ Chalcopyrite $\left(\mathrm{CuFeS}_{2}\right)$ and pyrite $\left(\mathrm{FeS}_{2}\right)$ were found to be the major constituents, with chalcocite $\left(\mathrm{Cu}_{2} \mathrm{~S}\right)$, covellite, $(\mathrm{CuS})$ and quartz $\left(\mathrm{SiO}_{2}\right)$ as minor constituents. The results of the particle characterization are discussed in the next section of this paper.

Once the characterization of the copper concentrate particles was completed, the experimental conditions for 
the oxidation tests were set according to the following reactions.

$$
\begin{gathered}
2 \mathrm{CuFeS}_{2(\mathrm{~s})}+\mathrm{O}_{2(\mathrm{~g})} \rightarrow \mathrm{Cu}_{2} \mathrm{~S}_{(\mathrm{l})}+2 \mathrm{FeS}_{(\mathrm{l})}+\mathrm{SO}_{2(\mathrm{~g})} \\
\mathrm{FeS}_{2(\mathrm{~s})}+\mathrm{O}_{2(\mathrm{~g})} \rightarrow \mathrm{FeS}_{(1)}+\mathrm{SO}_{2(\mathrm{~g})}
\end{gathered}
$$

It is noted that [1] and [2] represent the goal of the reaction chamber to produce matte. During the experiments, suspension-smelting conditions were established. The solid feed rate was set to the lowest possible value provided by the vibratory feeder, which varied in the range of 3 to $5 \mathrm{~g} / \mathrm{min}$ depending on the particle size of the feed material. Once the chemical composition of the concentrate particles was known and the solid feed rate was established, the stoichiometric amount of oxygen necessary to carry out reactions [1] and [2] was computed. The actual flow rate of oxygen gas supplied to the reactor was set to 1.3 times the stoichiometric amount, and that of nitrogen was calculated from a mass balance to satisfy the oxygen concentration to be tested in the run. Prior to the experiments, care was taken to verify that the total flow rate of process gas supplied to the reactor guaranteed laminar-flow conditions within the reaction chamber. This was accomplished by computing the average Reynolds number of the gas phase in the reactor and verifying that its value was less than 2100 . Typically, this quantity varied in the range of 400-670.

Prior to the experiments, extensive calibrations of the vibratory feeder and the gas rotameters were made. The oxidation tests were conducted with both the six sieved fractions and the unsieved concentrate particles, for a total of seven sizes. The oxygen concentration in the process gas was set to 40 and 70 pct by volume. The experimental design consisted of a $2 \times 7$ full factorial arrangement for all combinations of the input variables: oxygen concentration and particle size. For each experimental condition, seven vertical positions of the SFA were tested. The locations corresponded to receptacle samples collected at $0.2,0.3,0.4,0.5,0.6,0.8$, and $0.9 \mathrm{~m}$ from the lance tip. In a typical experiment, the furnace was first heated up while the SFA was placed at the corresponding position for the experiment. The solid feed rate was set depending on the particle size of the feed material, and the oxygen and nitrogen flow rates were adjusted to achieve the oxygen concentration to be tested. The process gas was allowed to flow through the reactor until the wall temperature readings stabilized, upon which the vacuum pump and the vibratory feeder were turned on. During the experiments, the temperature profile in the reactor experienced little variations. The isothermal zone in the reactor was about $0.7 \mathrm{~m}$ long with an average wall temperature of $1053 \mathrm{~K}$. During the oxidation tests, about $300 \mathrm{~g}$ of concentrate particles were fed to the furnace at the prespecified solid feed rate. The concentrate particles were oxidized as they flowed downwards with the gas and settled on the bottom of the water-cooled receptacle. The experiment proceeded for about 60 minutes, upon which the reacted particles were collected at the receptacle. To improve the quenching of particles, in some experiments the receptacle was surrounded by a bath of water and ice contained in a bucket. Upon collection, the samples were stored in plastic bags and labeled for further analysis. The size distributions of all sieved fractions, the unsieved material, and the reacted particles were determined by means of a Beckman Coulter LS100Q particle size analyzer based on a laser diffraction technique. For this purpose, $500 \mathrm{mg}$ of particles was suspended in $100 \mathrm{~mL}$ of distilled water contained in a glass flask. The solid-liquid suspension was then exposed to ultrasound for 5 minutes in a sonicator to disperse the particles. In a typical analysis, an aliquot of $3 \mathrm{~mL}$ of this suspension was injected into the particle size analyzer and the size distribution was measured. The values reported in this paper represent the average of 10 to 20 measurements. Chemical analyses of the reacted particles were conducted by gravimetry and AAS techniques to determine the amount of sulfur, copper, and iron. Further, the fraction of sulfur eliminated from the particles was determined from the following expression ${ }^{[11]}$

$$
S_{\text {elim }}=1-\frac{(\text { wt pct } S)_{\mathrm{s}}(\text { wt pct Fe })_{\mathrm{f}}}{(\text { wt pct })_{\mathrm{f}}(\text { wt pct Fe })_{s}},
$$

where subscripts $\mathrm{f}$ and $\mathrm{s}$ stand for feed and sample, respectively. Equation [3] is based on the fact that iron does not volatilize from the particles during oxidation. The amount of magnetic compounds in the particles was determined by means of a Satmagan balance, and the results reported as magnetite content. Microscopic examination of a selected number of samples was conducted in a scanning electron microscope (SEM) JEOL 5410 LV and the QEMSCAN ${ }^{\circledR}$ unit described previously. The evolution of size and morphology of the reacted particles was also analyzed by means of the QEMSCAN ${ }^{\circledR}$ unit. Prior to the analysis, about $0.68 \mathrm{~g}$ of sample was mounted on resin and the surface of the resulting probe was thoroughly polished. The probe was placed into the QEMSCAN ${ }^{\circledR}$ unit, which scanned the probe surface $\left(7 \mathrm{~cm}^{2}\right)$ to identify and count the particles. During a typical analysis, about 30,000 particles were identified, counted, and further sorted by size by the software built within the QEMSCAN ${ }^{\circledR}$ unit. The scanning resolution was set to $2 \mu \mathrm{m}$, which represents an area of $2 \times 2 \mu \mathrm{m}^{2}$ for each analysis.

\section{DISCUSSION OF RESULTS}

\section{A. Characteristics of the Initial Particles}

In this paper, the terms initial particles and feed particles are used as synonymous. The chemical composition of all sieved fractions and the unsieved concentrate determined by AAS and gravimetry techniques are shown in Figure 3. The results showed that the copper content in the particles decreased as the particle size increased, whereas the iron and sulfur contents showed the opposite trend. In contrast, the amount of gangue represented by silicon and other elements was fairly uniform throughout the population. Of special 
interest is the fact that the chemical composition of the unsieved concentrate showed intermediate values between the finest $(<45 \mu \mathrm{m})$ and largest $(>149 \mu \mathrm{m})$ sieved fractions. This suggested that the species composition was size dependent. To verify this hypothesis, the XRD analyses of all sieved fractions and the unsieved concentrate were conducted. The results shown in Figure 4 indicated that particles in all size fractions mostly consisted of chalcopyrite and pyrite, with small amounts of chalcocite, covellite, and quartz. A general inspection of Figure 4 indicated that chalcopyrite was the predominant species in the finest fraction $<45 \mu \mathrm{m}$, whereas pyrite was predominant in the coarsest fraction

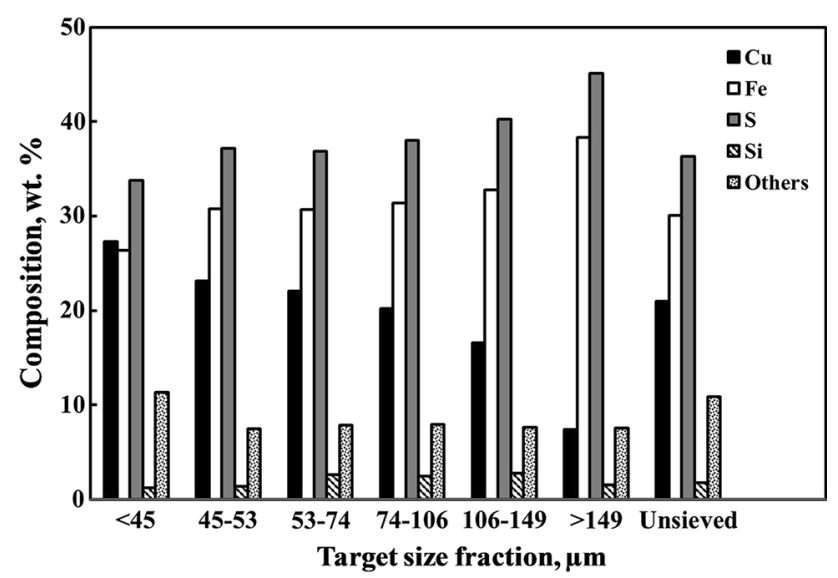

Fig. 3- Chemical composition of La Caridad copper concentrate particles. Values shown are the average obtained from AAS and QEMSCAN ${ }^{\circledR}$ analyses.
$>149 \mu \mathrm{m}$. Particles in the range of 45 to $149 \mu \mathrm{m}$ contained both species in varying proportions, whereas the results for the unsieved concentrate resembled those obtained with fraction 45 to $53 \mu \mathrm{m}$. Based on the information provided by Figures 3 and 4, a quantitative estimation of the phases present in the particles was made with the mineralogy iteration module built in the HSC software. ${ }^{[34]}$ The results shown in Figure 5 confirmed that the species composition was strongly size dependent. Overall, the content of chalcopyrite decreased as the size fraction increased, whereas the opposite trend was observed for the content of pyrite.

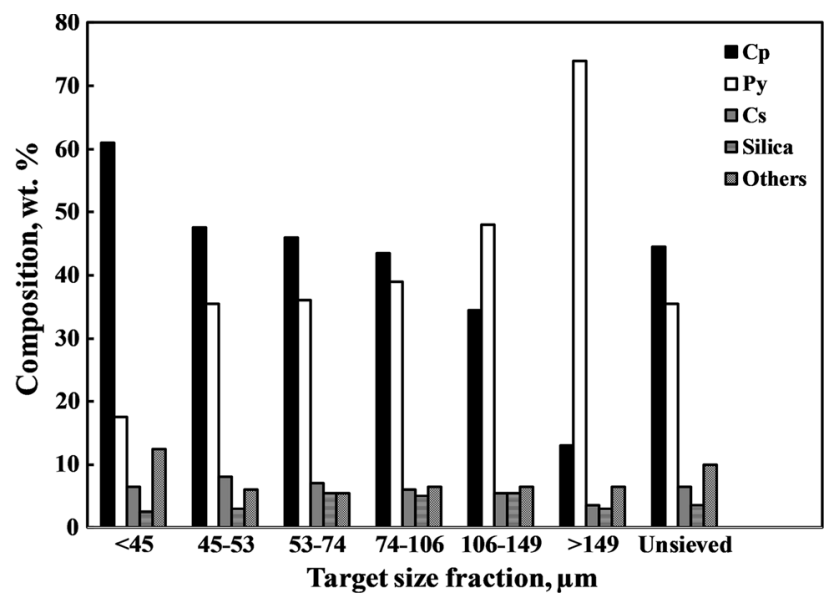

Fig. 5-Mineralogical composition of La Caridad copper concentrate particles estimated with the HSC software ${ }^{[34]}$. Cp: chalcopyrite; Py: pyrite; Cs: copper sulfides (chalcocite + covellite).

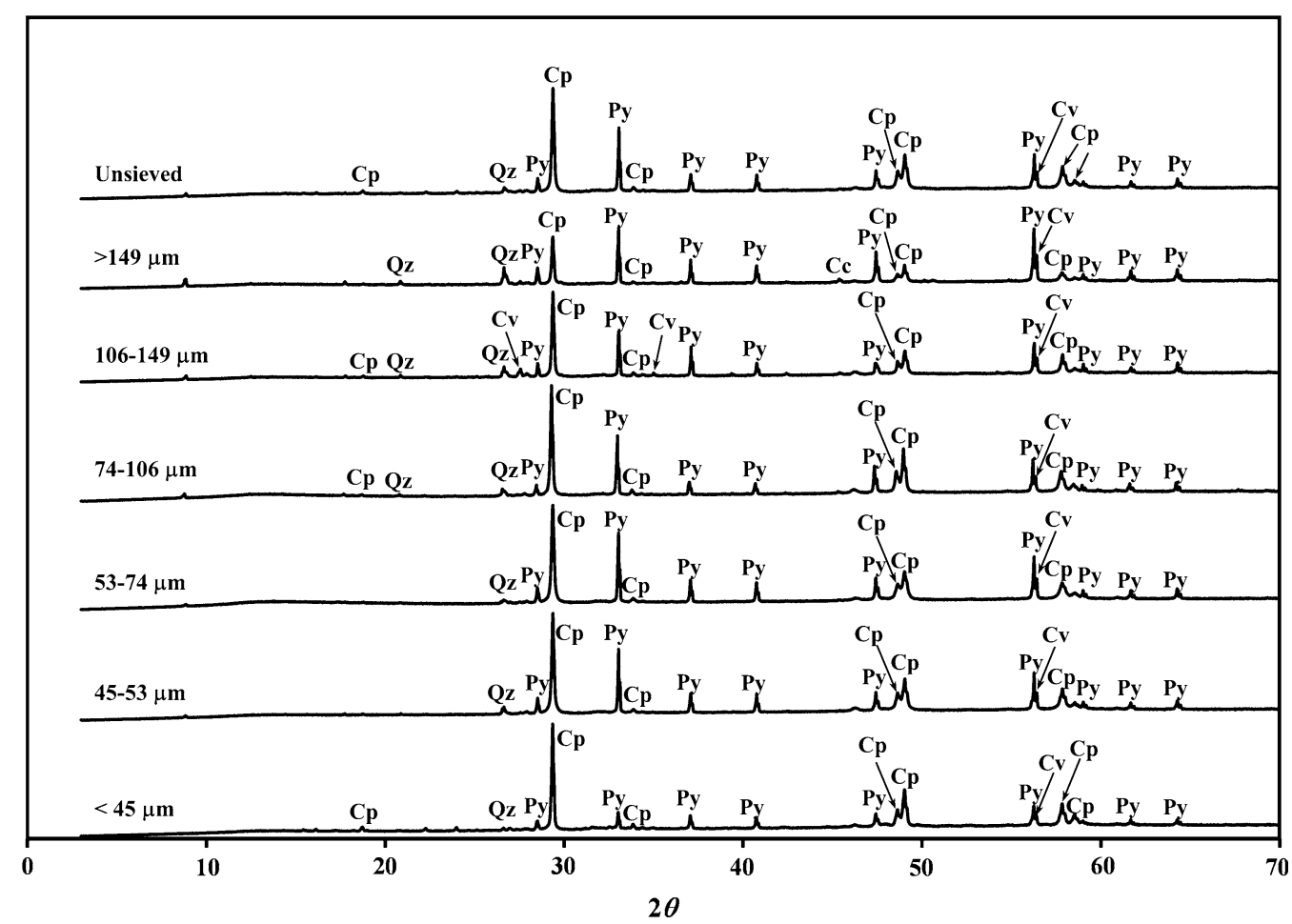

Fig. 4 -XRD results of La Caridad copper concentrate particles; Cp: chalcopyrite; Py: pyrite; Cc: chalcocite; Cv: covellite; Qz: quartz. 
As expected, the average composition of the unsieved concentrate was a combination of the values of all sieved fractions.

To elucidate the mineralogical associations of the species in the original particles, a liberation analysis was conducted by means of the QEMSCAN ${ }^{\circledR}$ unit. The results, which are not shown here for the sake of brevity, indicated that the degree of liberation of both chalcopyrite and pyrite increased as the size fraction decreased. This was expected because the concentrate was obtained by a previous step of grinding. The amount of free chalcopyrite and free pyrite particles in the finest fraction $<45 \mu \mathrm{m}$ represented, respectively, 86 and 85 pct of the total amount of each species in this fraction. The lowest liberation values corresponded to the coarsest fraction $>149 \mu \mathrm{m}$, with 44 and 67 pct for chalcopyrite and pyrite, respectively. The degree of liberation in the unsieved concentrate strongly resembled that of fraction $<45 \mu \mathrm{m}$. From this information, the overall composition in terms of the associations of the major species was obtained. The results are shown in Figure 6. Here, all values represent the amount of the given species in the total mass of the population, in wt pct. The values in parentheses indicate the summation of free chalcopyrite and free pyrite contents. This quantity varied in the range of 55 to $68 \mathrm{pct}$, with the largest value corresponding to fraction $<45 \mu \mathrm{m}$. As the target size fraction increased, the amount of free chalcopyrite particles decreased and the amount of free pyrite particles increased. Furthermore, the largest sieved fraction $>149 \mu \mathrm{m}$ contained 51 pct of free pyrite particles. Figure 6 indicated that the original material largely consisted of a mixture of free chalcopyrite and free pyrite particles in proportions which varied with the target sieved fraction. For the unsieved concentrate, the amount of free chalcopyrite and free pyrite particles represented 66 pct of the entire population.

The frequency size distributions of the initial particles determined by the laser diffraction technique are shown

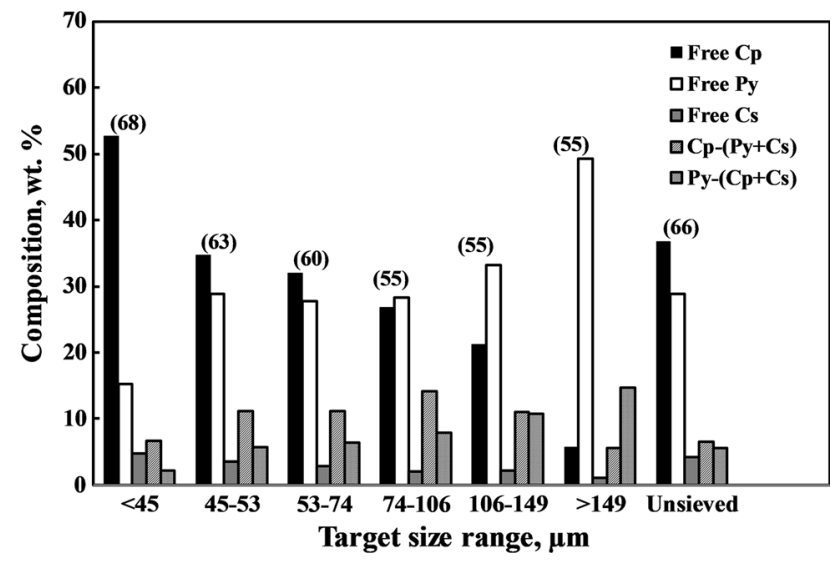

Fig. 6-Mineralogical composition of La Caridad copper concentrate particles in terms of the associations of the major species. Cp: chalcopyrite; Py: pyrite; Cs: copper sulfides (chalcocite + covellite); $\mathrm{Cp}-(\mathrm{Py}+\mathrm{Cs})$ : chalcopyrite associated with pyrite and copper sulfides; Py - $(\mathrm{Cp}+\mathrm{Cs})$ : pyrite associated with chalcopyrite and copper sulfides. All values represent the percentage of the total mass of the population; the values in parentheses indicate the summation of free chalcopyrite and free pyrite contents. in Figure 7, in which a logarithmic scale was used for the horizontal axis. For simplicity, the bars representing the variability of the experimental data are not shown. Based on the replicated measurements of the size distributions, the standard deviation of the experimental values of $v_{i}$ was found to be in the range of 0.003 to 0.83 vol pct. The mean size $\langle x\rangle$ and standard deviation $\sigma$ of the populations were determined from the following expressions, respectively,

$$
\langle x\rangle=\frac{1}{100} \sum_{i=1}^{N} x_{i} v_{i}
$$

and

$$
\sigma=\frac{1}{10} \sqrt{\sum_{i=1}^{N}\left(x_{i}-\langle x\rangle\right)^{2} v_{i}},
$$

where $v_{i}$ is the volume percentage of the particle population occupied by size $x_{\mathrm{i}}$, and $N$ is the number of discretized sizes in the population. Table I summarizes the statistics of all size fractions and the unsieved concentrate relevant for the present study.

The coefficient of variation $(C V)$ defined in Table $\mathrm{I}$ is a dimensionless indicator of the dispersion of sizes in the population with respect to the mean size $\langle x\rangle$. This quantity was less than unity in all sieved fractions, which indicates a good sieving efficiency. In contrast, the value of $C V$ for the unsieved concentrate $(C V=1.1)$ indicates that the size distribution was broadly spread around its mean size, as is evident in Figure 7. In this work, dust is defined as any particle within the size range of 0 to $20 \mu \mathrm{m}$, regardless of its origin and chemical composition. $^{[35]}$ The volume fraction of dust in the population $F_{\mathrm{d}}$ was determined from the following expression

$$
F_{\mathrm{d}}=\frac{1}{100} \sum_{i=1}^{d} v_{i},
$$

where $d$ is the discretized size at which: $x_{\mathrm{d}}=20 \mu \mathrm{m}$. Table I shows that this quantity varied in the range of

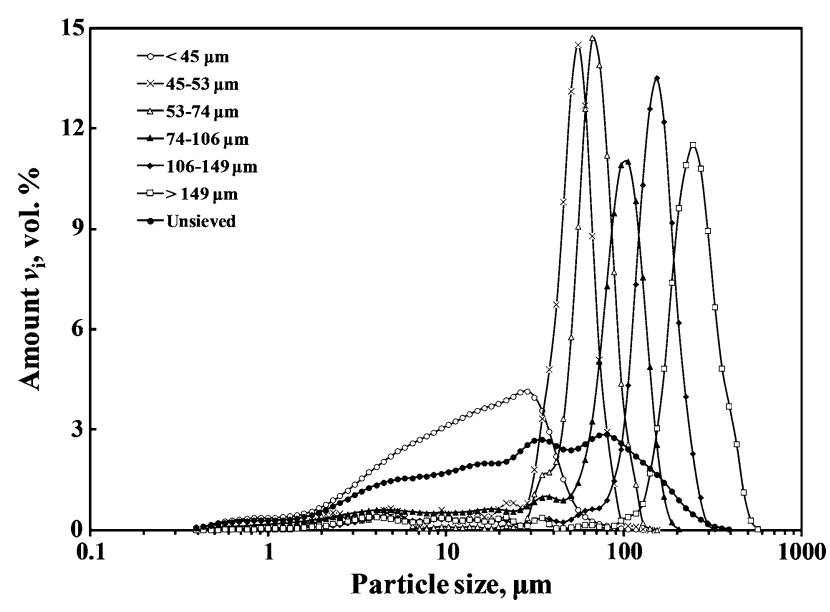

Fig. 7-Frequency size distributions of sieved fractions and unsieved concentrate determined by size analyzer Beckman Coulter LS100Q. 
Table I. Characteristics of Wet-Sieved Fractions and Unsieved La Caridad Copper Concentrate Particles

\begin{tabular}{lccc}
\hline Target Size Range $(\mu \mathrm{m})$ & $\langle x\rangle(\mathrm{m})$ & $C V=\sigma /\langle x\rangle$ & $F_{\mathrm{d}}$ \\
\hline$<45$ & 17 & 0.82 & 0.67 \\
45 to 53 & 48 & 0.42 & 0.12 \\
53 to 74 & 64 & 0.36 & 0.06 \\
74 to 106 & 82 & 0.52 & 0.16 \\
106 to 149 & 140 & 0.41 & 0.07 \\
$>149$ & 231 & 0.44 & 0.08 \\
Unsieved & 49 & 1.1 & 0.42 \\
\hline
\end{tabular}

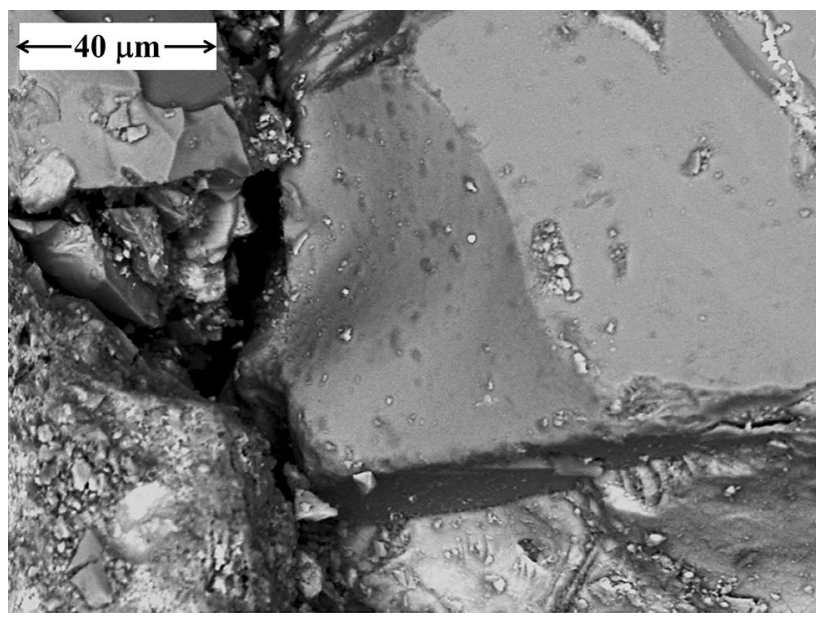

Fig. 8 - SEM image of particles of size fraction $>149 \mu \mathrm{m}$ showing fine particles attached to the surface and filling up the interstices of fractures and edges.

0.06 to 0.67 in the original material. To find out the origin of dust particles in the sieved fractions of large sizes, microscopic examination of the samples was conducted. The SEM images showed fine particles attached to the surface of large particles and filling up the fractures and interstices of particle edges (Figure 8). Such observations explain the presence of dust in all sieved fractions obtained. Because of the strong forces acting between these particles, they could not be removed by wet sieving.

\section{B. Sulfur Elimination and Chemical Composition of Reacted Particles}

The characterization of the initial particles discussed previously was the basis for the following analysis. Upon inspection of the experimental data, it was found that the oxygen concentration in the process gas did not play a significant role on the response variables when it was varied in the range of 40 to $70 \mathrm{vol}$ pct. Therefore, the following discussion is focused on the results obtained under 70 pct $\mathrm{O}_{2}$, which is the typical oxygen concentration in the industrial operation. Figure 9 shows the profiles of sulfur eliminated from the particles determined from Eq. [3]. Although some scattering of the experimental data is observed, it is noted that the onset of sulfur removal was dependent on the initial size.

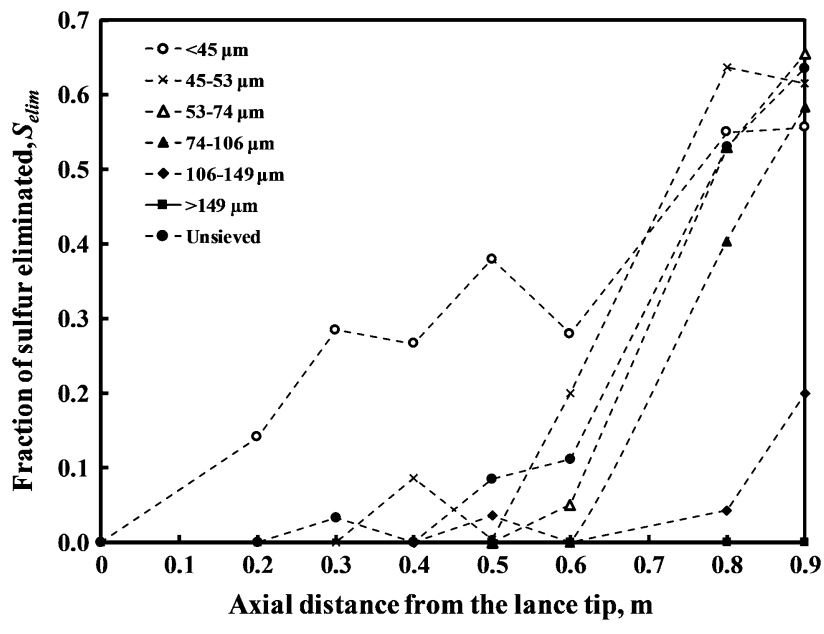

Fig. 9-Profiles of sulfur eliminated from the particles along the reactor. Experiments conducted under 70 pet $\mathrm{O}_{2}$ in the process gas.

As expected, the larger the initial particles the longer the distance from the lance tip at which the removal of sulfur was initiated. Whereas the finest particles $<45 \mu \mathrm{m}$ lost sulfur at $0.2 \mathrm{~m}$ from the lance tip, other sieved fractions initiated the removal of sulfur beyond $0.4 \mathrm{~m}$. Furthermore, the largest particles $>149 \mu \mathrm{m}$ remained mostly unreacted during flight. These results are reasonable because the onset of sulfur removal is related to particle ignition, which is determined by the heat transfer conditions surrounding the particles. For single concentrate particles traveling along the reactor, the smaller their size the shorter the time to achieve ignition. This is because the heat necessary to achieve ignition is proportional to the particle mass. The slope of the curves in Figure 9 represents the rate of sulfur removal from the particles. Figure 9 shows that the removal of sulfur from particles within the finest fraction $<45 \mu \mathrm{m}$ occurred gradually along the reactor. In contrast, particles of other sieved fractions (45 to 53, 53 to 74,74 to $106 \mu \mathrm{m}$ ) lost sulfur rapidly as soon as they reached their ignition temperature, which is the expected behavior for the oxidation of individual particles. ${ }^{[36]}$ The trend followed by fraction $<45 \mu \mathrm{m}$ does not agree with the reaction path shown in Figure 1. Such a trend may be explained in terms of an alternative reaction path in which the smallest particles in the feed undergo rapid melting and collide to each other to create new large droplets during flight. This hypothesis, which has been proposed in the past to explain the oxidation behavior of fine concentrate particles, ${ }^{[9,20,23,25,26]}$ agreed well with other observations regarding the morphology and size of the reacted particles, and is discussed in Section III-D of this paper.

A complementary indicator of the particle reaction path is the relative amount of magnetic species in the particles. Such species may include cuprospinel $\left(\mathrm{CuFe}_{2} \mathrm{O}_{4}\right)$, delafossite $\left(\mathrm{CuFeO}_{2}\right)$, and magnetite $\left(\mathrm{Fe}_{3} \mathrm{O}_{4}\right)$. This quantity was determined by the Satmagan balance as a single composition and expressed as content of magnetite in wt pct. Figure 10 shows the evolution of this quantity. Overall, the trends observed 
are similar to those shown in Figure 9. Therefore, the formation of magnetic species in the particles was accompanied by sulfur elimination and vice versa. At the reactor exit, the content of magnetic species reached values as high as 40 pct by weight. On the other hand, its value in particles of size $<45 \mu \mathrm{m}$ at the reactor exit (20 pct) was substantially smaller than those obtained for other sieved fractions (45 to 53,53 to 74,74 to $106 \mu \mathrm{m})$ and the unsieved concentrate, which varied in the range of 34 to 41 pct. Such a behavior deviated from that observed in Figure 9, and suggests that for the finest particles, the oxidation reactions involving the formation of magnetic species explains only partially the

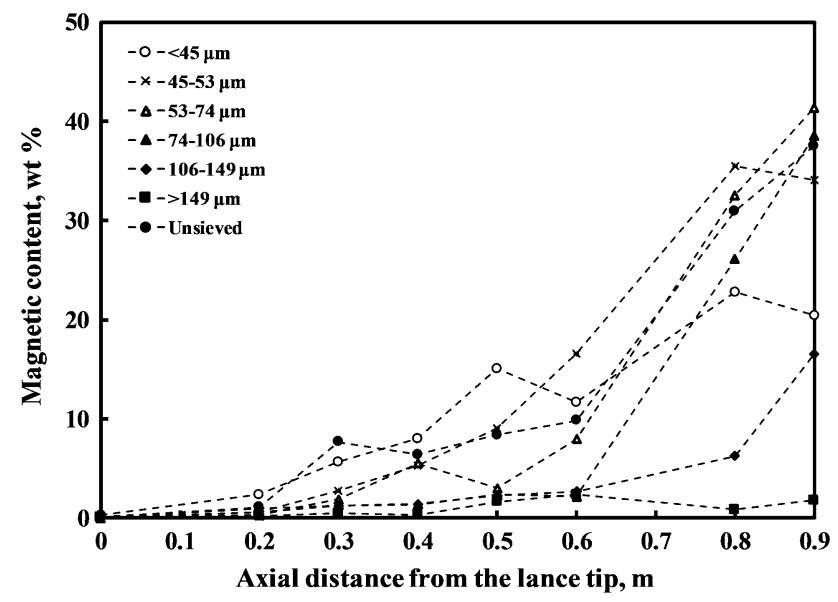

Fig. 10-Profiles of magnetic content of particles for experiments conducted under 70 pct $\mathrm{O}_{2}$ in the process gas. amount of sulfur eliminated from the particles. In contrast, for other sieved fractions and the unsieved concentrate the correlation between the amount of sulfur eliminated and the content of magnetic species was clear.

To determine the major oxidation products in the reacted particles, XRD analyses of selected samples collected at $0.9 \mathrm{~m}$ from the lance tip were conducted. This corresponds to those particles that spent the longest residence time in the reactor. Figure 11 shows the XRD results of particles within fractions $<45$ and 45 to $53 \mu \mathrm{m}$, as well as the unsieved concentrate, which are shown as examples. The major oxidation products detected in all samples included magnetite and hematite. A strong peak indicated by the asterisk in Figure 11 was difficult to identify, as it was possibly due to overlapping signals from cuprospinel and magnetite. It is noted that all XRD results showed the presence of unreacted chalcopyrite, whereas no residual signals of pyrite were detected. This agrees with previous observations ${ }^{[9]}$ that indicate that pyrite is more reactive than chalcopyrite under similar oxidation conditions. A mineralogical analysis of the reacted particles was also conducted by means of the QEMSCAN ${ }^{\circledR}$ unit, this included EDS analyses at specific spots within selected particles. The results are shown in Figure 12. The detection of a "copper-iron sulfide" phase in all samples matched the XRD results regarding the presence of unreacted chalcopyrite, which constituted the major phase in the particle population (36 to $44 \mathrm{pct}$ ). The "iron oxide" phase (12 to $19 \mathrm{pct}$ ) closely matched the chemical formula of magnetite. A significant result in Figure 12 was the detection of a "copper-iron oxide" phase ( 7 to

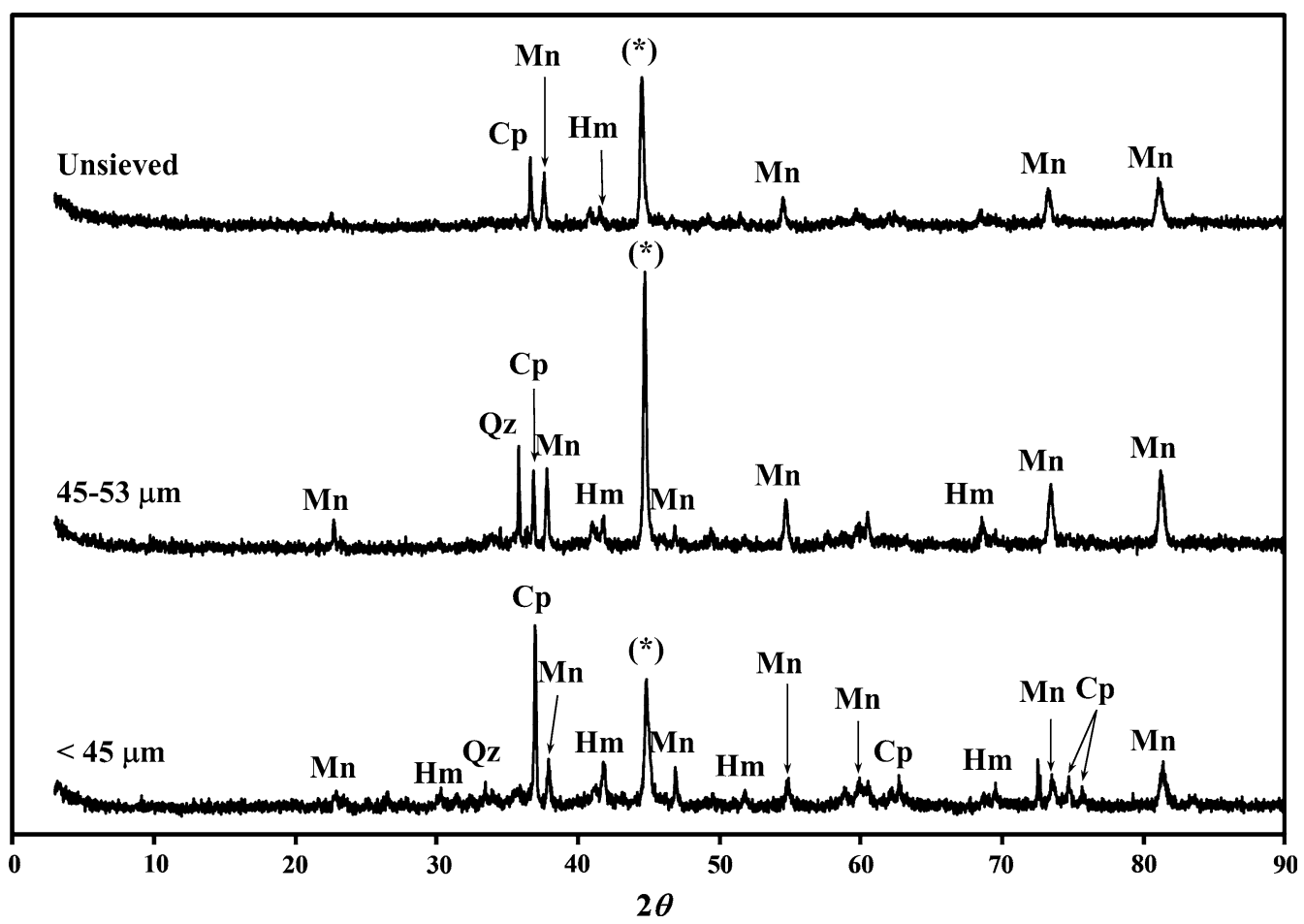

Fig. $11-\mathrm{XRD}$ results of reacted particles collected at $0.9 \mathrm{~m}$ from the lance tip under 70 pct $\mathrm{O}_{2}$ in the process gas; Cp: chalcopyrite; Mn: magnetite; Hm: hematite; Dg: digenite; Qz: quartz; (*): cuprospinel/magnetite. 


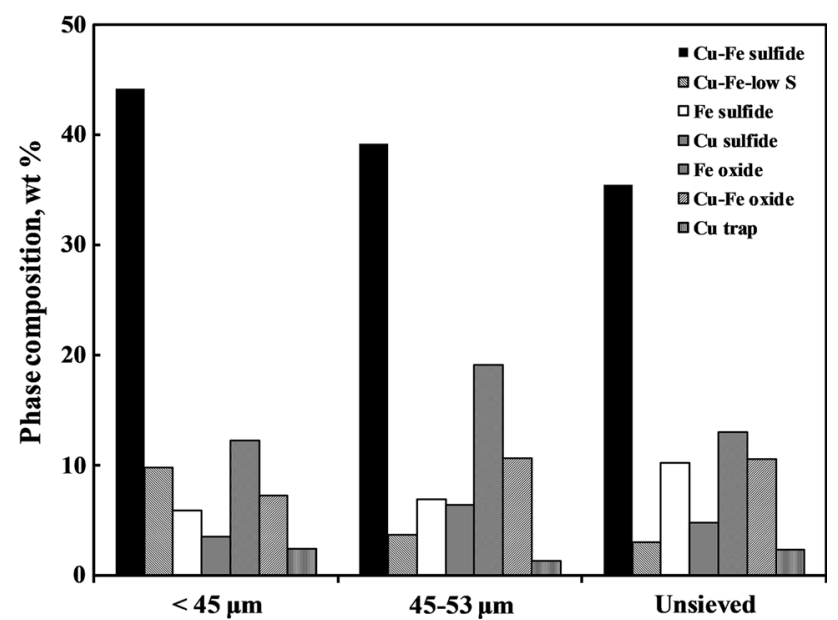

Fig. 12-Phase composition of reacted particles collected at $0.9 \mathrm{~m}$ from the lance tip under 70 pct $\mathrm{O}_{2}$ in the process gas. Results obtained by QEMSCAN ${ }^{\circledR}$ analysis.

$11 \mathrm{pct}$ ), which suggested the presence of cuprospinel. The following phases found by the QEMSCAN ${ }^{\circledR}$ unit were not detected in the XRD analysis, possibly due to their low content in the particles: a sulfur-deficient copper-iron sulfide phase designated as "copper iron sulfide-low S" (3 to $10 \mathrm{pct}$ ), an "iron sulfide" phase which closely matched the chemical formula of pyrite $(6$ to 10 pct), a "copper sulfide" phase (4 to 6 pct), and a "copper trap" phase (1 to 2 pct).

It is emphasized that the results shown in Figure 12 are semiquantitative, and thus are approximate. They complement the XRD results (Figure 11) to provide an overall picture of the major phases present in the reacted particles. The results obtained in this study agreed well with previous observations by other authors ${ }^{[23,36]}$ who found that the oxidation of chalcopyrite-based copper concentrate particles produced a variety of products depending on the operating conditions in the reactor and the composition of the initial particles. Whereas the stoichiometry of the chemical reactions occurring in the particles is still uncertain, several routes have been proposed in the literature to explain the experimental observations. ${ }^{[10,11,16,17,22,36,37]}$ The following discussion is based on the results obtained in this work. At the initial stages of heating, it is likely that chalcopyrite underwent thermal decomposition to produce a sulfur-deficient copper-iron sulfide phase as suggested by Jorgensen and $\mathrm{Koh}^{[17]}$

$$
\mathrm{CuFeS}_{2} \rightarrow \mathrm{CuFeS}_{2-w}+\frac{w}{2} \mathrm{~S}_{2(\mathrm{~g})},
$$

where $w$ is the number of atoms of sulfur volatilized per molecule of chalcopyrite. Other authors ${ }^{[10,11,16]}$ suggested that the thermal decomposition of chalcopyrite produces bornite, pyrrhotite, elemental iron, and sulfur gas, whereas Ahokainen et al. ${ }^{[37]}$ suggested that bornite, iron sulfide, and atomic sulfur are formed. In this work, no elemental iron and atomic sulfur were detected in the particles. Another possible route was proposed by Hagni et al. ${ }^{[22]}$ and involves the oxidation of solid chalcopyrite to produce bornite, hematite, and sulfur dioxide gas:

$$
5 \mathrm{CuFeS}_{2}+9 \mathrm{O}_{2(\mathrm{~g})} \rightarrow \mathrm{Cu}_{5} \mathrm{FeS}_{4}+2 \mathrm{Fe}_{2} \mathrm{O}_{3}+6 \mathrm{SO}_{2(\mathrm{~g})} \quad[8
$$

Further oxidation of chalcopyrite up to $873 \mathrm{~K}$ possibly occurred to produce copper sulfate, hematite, and sulfur dioxide gas according to ${ }^{[36]}$

$$
4 \mathrm{CuFeS}_{2}+15 \mathrm{O}_{2(\mathrm{~g})} \rightarrow 4 \mathrm{CuSO}_{4}+2 \mathrm{Fe}_{2} \mathrm{O}_{3}+4 \mathrm{SO}_{2(\mathrm{~g})}[9]
$$

Upon ignition, it is likely that chalcopyrite oxidized according to reaction [1] to produce a mixture of copper and iron sulfides, i.e., copper matte. Further, under excess of oxygen in the laboratory reactor, the matte oxidized to form cuprospinel and copper oxide according to the following reaction ${ }^{[36]}$

$$
\begin{gathered}
\mathrm{Cu}_{2} \mathrm{~S}+y \mathrm{FeS}_{x}+z \mathrm{O}_{2} \rightarrow \frac{y}{2} \mathrm{CuFe}_{2} \mathrm{O}_{4} \\
+(1-0.25 y) \mathrm{Cu}_{2} \mathrm{O}+(1+x y) \mathrm{SO},
\end{gathered}
$$

where $x$ is the number of sulfur atoms per atom of iron in the concentrate, $y$ is the number of moles of iron sulfide per mole of copper sulfide in the molten sulfide phase, and $z=1+0.875 y+0.5 x y$. The SO formed from reaction [10] is further oxidized in the gas phase to produce $\mathrm{SO}_{2}$. Sohn and Chaubal ${ }^{[36]}$ found that the incorporation of reaction [10] into a kinetic model for the oxidation of copper concentrate particles under suspension-smelting conditions provided good agreement with the temperature measurements reported by Jorgensen ${ }^{[9]}$ in a laboratory reactor. On the other hand, the small amounts of hematite found in the particles suggest that pyrite mostly oxidized to form magnetite and sulfur dioxide gas according to the following reaction:

$$
3 \mathrm{FeS}_{2}+8 \mathrm{O}_{2(\mathrm{~g})} \rightarrow \mathrm{Fe}_{3} \mathrm{O}_{4}+6 \mathrm{SO}_{2(\mathrm{~g})}
$$

Because both chalcopyrite and pyrite were highly liberated in the concentrate, little interaction between both phases was expected. It is noted that reactions [1] and [7] to [11] involve the loss of sulfur from the particles, whereas reactions [10] and [11] produce species with magnetic properties, i.e., cuprospinel $\left(\mathrm{CuFe}_{2} \mathrm{O}_{4}\right)$ and magnetite $\left(\mathrm{Fe}_{3} \mathrm{O}_{4}\right)$, respectively.

\section{Mean Size and Dust Content}

Figures 13 and 14 show the evolution of the cumulative size distributions for fractions: $<45$ and 45 to $53 \mu \mathrm{m}$, which are shown here as examples. The results obtained with other size fractions were similar to those shown in Figure 14, and thus are not presented here. Overall, the curves for fraction $<45 \mu \mathrm{m}$ (Figure 13) gradually shifted to the right, i.e., the sizes in the population in general increased as the particle population traveled through the reactor. This trend suggests that collision and coalescence of droplets occurred during flight. In contrast, for the sieved fraction 45 to $53 \mu \mathrm{m}$ (Figure 14) the curves gradually shifted to the left, thus indicating that the sizes in the population decreased upon oxidation. The latter results suggest that 


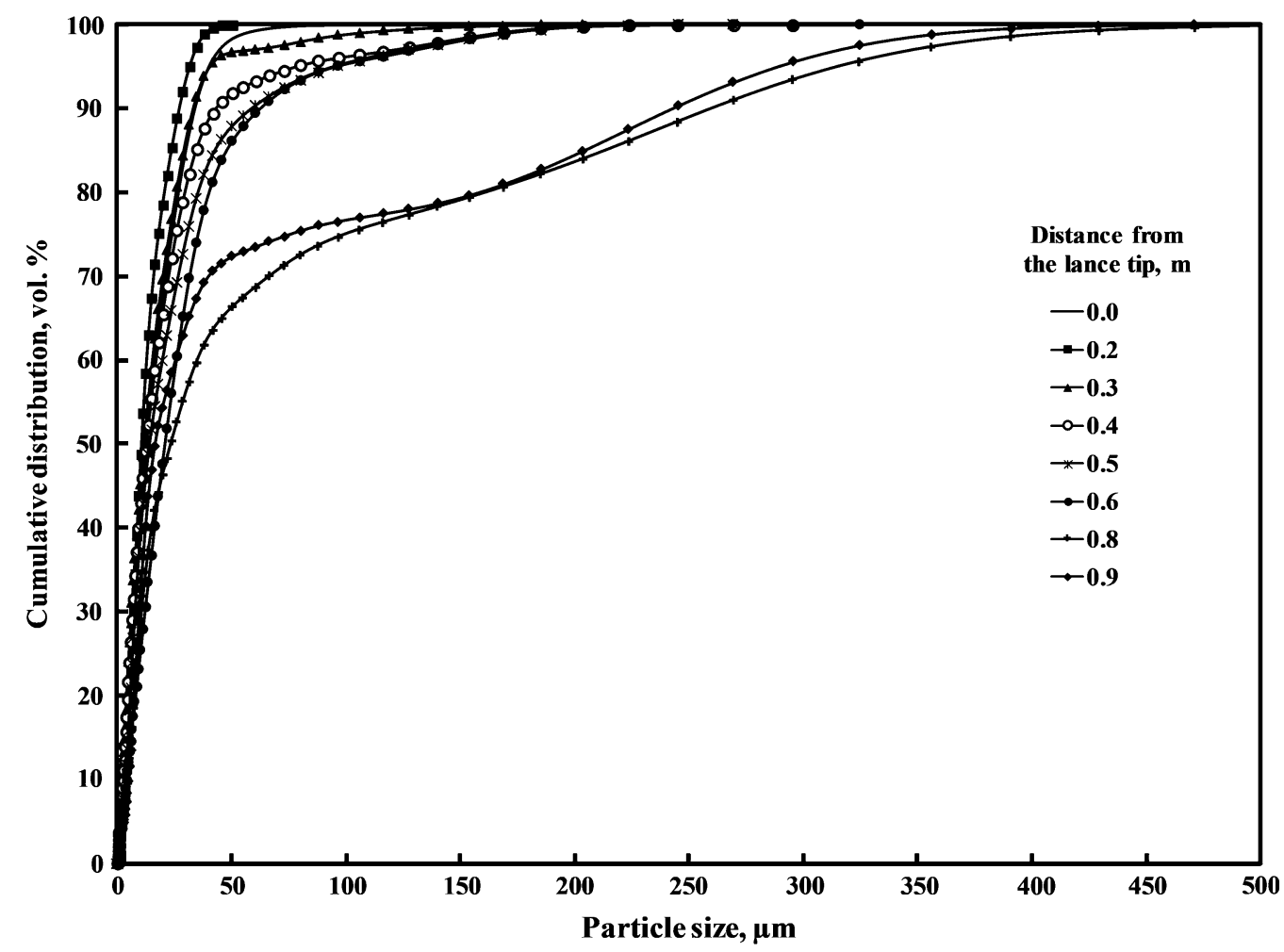

Fig. 13-Cumulative size distribution of particles along the laboratory furnace, 70 pct $\mathrm{O}_{2}$ in the process gas, size fraction $<45 \mu \mathrm{m}$.

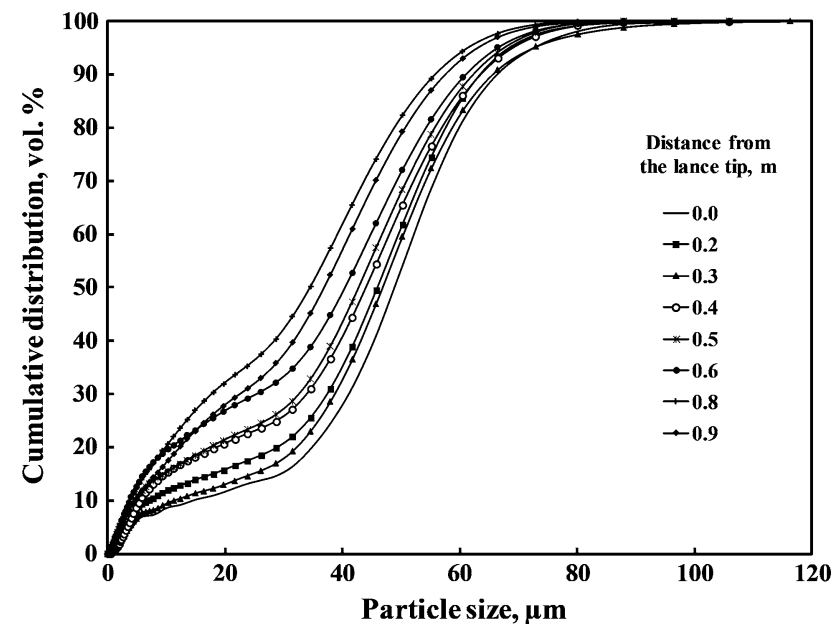

Fig. 14 - Cumulative size distribution of particles along the laboratory furnace, 70 pct $\mathrm{O}_{2}$ in the process gas, size fraction 45 to $53 \mu \mathrm{m}$.

particle fragmentation occurred according to the reaction path shown in Figure 1. The cumulative size distributions of the unsieved concentrate shown in Figure 15 strongly resembled those of fraction $<45 \mu \mathrm{m}$. This result was expected because particles within the fraction $<45 \mu \mathrm{m}$ made up about 79 pct of the volume of the unsieved concentrate, as can be inferred from the values shown in Figure 7.

Based on the experimental measurements of the size distributions, the mean size of the population was obtained from Eq. [3]. The results (Figure 16) show that the finest particles $<45 \mu \mathrm{m}$ and the unsieved

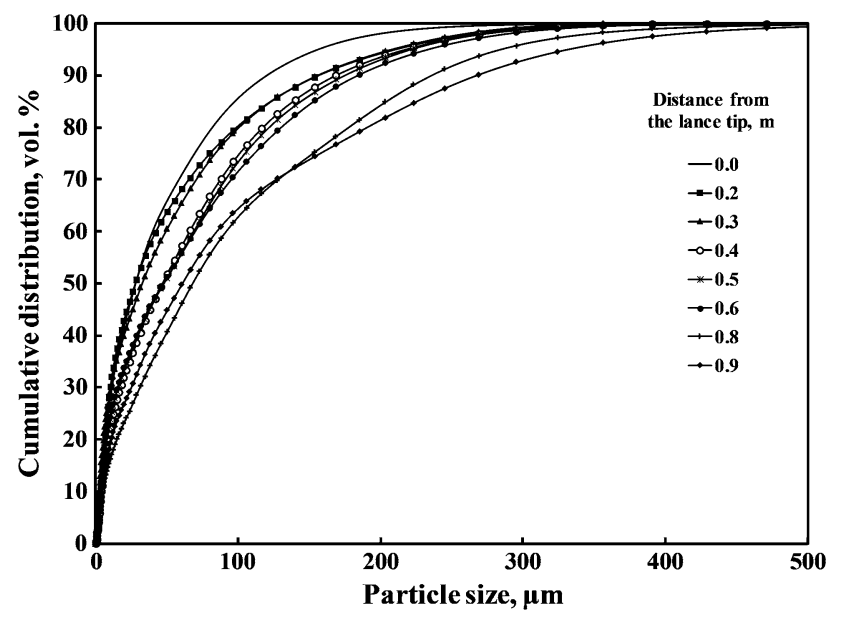

Fig. 15- Cumulative size distribution of particles along the laboratory furnace, 70 pct $\mathrm{O}_{2}$ in the process gas, unsieved concentrate.

concentrate clearly increased their mean size upon oxidation. In contrast, particles within the fractions: 45 to 53,53 to 74 , and 74 to $106 \mu \mathrm{m}$ decreased its mean size along the reactor. Finally, particles within the size fractions 106 to 149 and $>149 \mu \mathrm{m}$ fairly maintained their mean size. The evolution of the volume fraction of dust in the population obtained from Eq. [6] is shown in Figure 17. It is noted that the sieved fractions 45 to 53 and 53 to $74 \mu \mathrm{m}$ consistently generated dust during oxidation because of particle fragmentation. In contrast, particles with nominal sizes larger than $74 \mu \mathrm{m}$ showed no significant changes in the volume fraction of dust upon oxidation. Finally, the finest fraction $<45 \mu \mathrm{m}$ and 


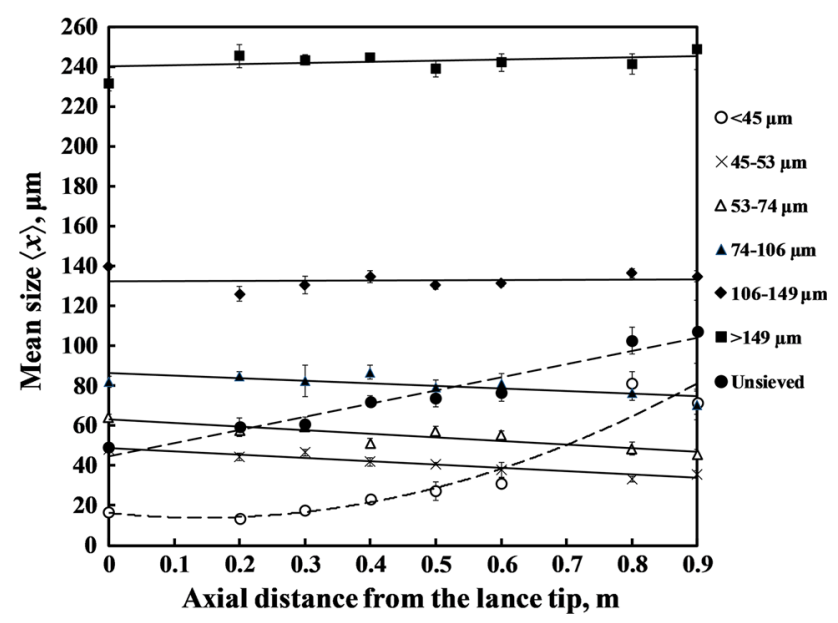

Fig. 16-Profiles of mean size of the population for all experiments conducted with 70 pct $\mathrm{O}_{2}$ in the process gas.

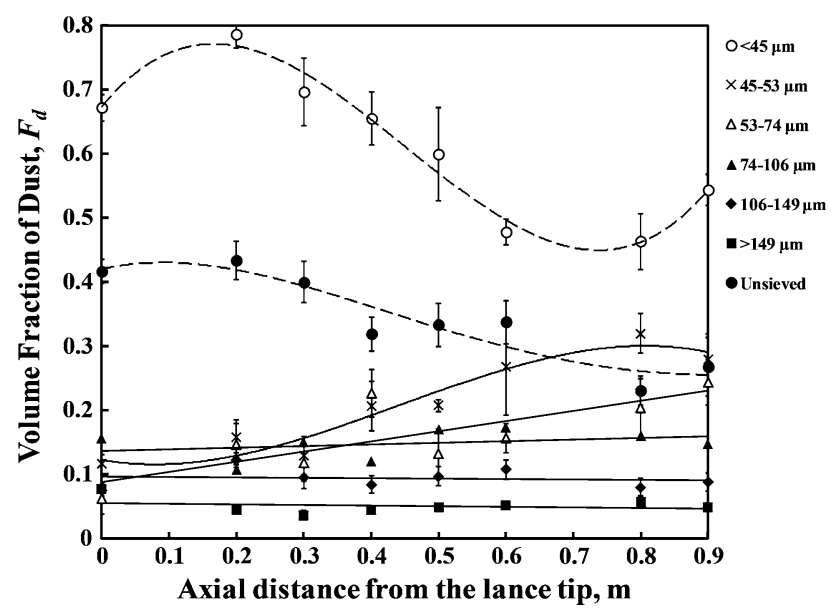

Fig. 17-Profiles of volume fraction of dust in the population for all experiments conducted under 70 pct $\mathrm{O}_{2}$ in the process gas.

the unsieved concentrate represented by the dashed lines clearly tended to decrease the amount of dust in the population due to collisions and coalescence of droplets during flight. This last result may seem contradictory to the general perception of plant operators, which establishes that flash smelting reactors typically produce significant amounts of dust when fine particles are fed to the reactor. However, it is emphasized that plant engineers usually call "dust" to all particles reaching the waste-heat boiler and electrostatic precipitator, regardless of their origin and size. In the present work, the term "dust" is restricted to particles with sizes in the range of 0 to $20 \mu \mathrm{m}$ which are associated with the reaction path only, i.e., the effect of entrainment in the gas phase as a result of turbulent dispersion is not considered.

\section{Morphology and Reaction Path of Particles}

Overall, Figures 9 through 17 showed that the oxidation behavior of the finest fraction $<45 \mu \mathrm{m}$ was substantially different from that observed for other sieved fractions. Similar observations were reported in the past by other authors. Jorgensen ${ }^{[9]}$ noted that chalcopyrite concentrate particles with sizes $<37 \mu \mathrm{m}$ fairly maintained its mean size, whereas sieved fractions of larger sizes tended to decrease their mean size upon oxidation. He also noted that the elimination of sulfur achieved by the size fractions $<37$ and 37 to $53 \mu \mathrm{m}$ was essentially the same, which was not expected for particles traveling individually. Jokilaakso et al.$^{[11]}$ made similar observations regarding the fraction 28 to $38 \mu \mathrm{m}$ of chalcopyrite concentrate. During oxidation tests with high-grade copper matte particles, Perez-Tello et al. ${ }^{[21]}$ observed that particles of fraction $<37 \mu \mathrm{m}$ tended to increase their size upon oxidation, whereas large particles decreased their size with substantial generation of dust. In a previous study with La Caridad copper concentrate particles, Thomas et al. ${ }^{[16]}$ noted that particles of fraction 25 to $38 \mu \mathrm{m}$ were less reactive than those of fraction 45 to $53 \mu \mathrm{m}$. Because particle reactivity is expected to decrease as the particle size increases, the authors attributed this behavior to the size dependency of particle composition, which showed a similar trend to that observed in Figure 7 of the present study.

To provide additional clues on this subject, microscopic examination of the samples was conducted. Figure 18(a) shows an SEM image of the initial particles of fraction $<45 \mu \mathrm{m}$, which were typically nonporous with irregular shapes and angular edges. A wide range of sizes in the population was observed. Upon oxidation (Figure 18(b)), many spherical particles with varied sizes were observed, which showed evidence of particle melting, while others retained an irregular shape. Many spherical particles with sizes significantly larger than the initial sizes were found, some of which showed holes on their surface, thus suggesting that fragmentation occurred with ejection of the molten material contained in the interior.

Figure 19 shows typical QEMSCAN ${ }^{\circledR}$ images of particles of size fraction $<45 \mu \mathrm{m}$ collected at several locations along the reactor. Because the number of particles recorded in a typical QEMSCAN ${ }^{\circledR}$ analysis was about 30,000 , only the portion corresponding to the largest particles found in the populations is shown. For comparison purposes, a common length scale is provided. The image labeled as " $0 \mathrm{~m}$ " corresponds to the feed to the reactor. Figure 19 shows a gradual change in both size and morphology of the particles. Whereas in the feed they were irregular and with maximum size of about $80 \mu \mathrm{m}$, at $0.3 \mathrm{~m}$ from the lance tip the largest particles became round and some showed internal cavities, thus suggesting that sulfur dioxide gas evolved from those particles. At $0.5 \mathrm{~m}$ from the lance tip, the number of round particles increased considerably throughout the population; the largest particles found here were about $180 \mu \mathrm{m}$ in size and showed evidence of melting. The size of the cavities also increased, as well as the thickness of the particle surface. Finally, at 0.8 and $0.9 \mathrm{~m}$ from the lance tip, the largest particles in the population were substantially larger than the initial particles, of the order of $300 \mu \mathrm{m}$. In general, the largest particles in the population at all sampling locations were typically round. This indicates that partial or full 

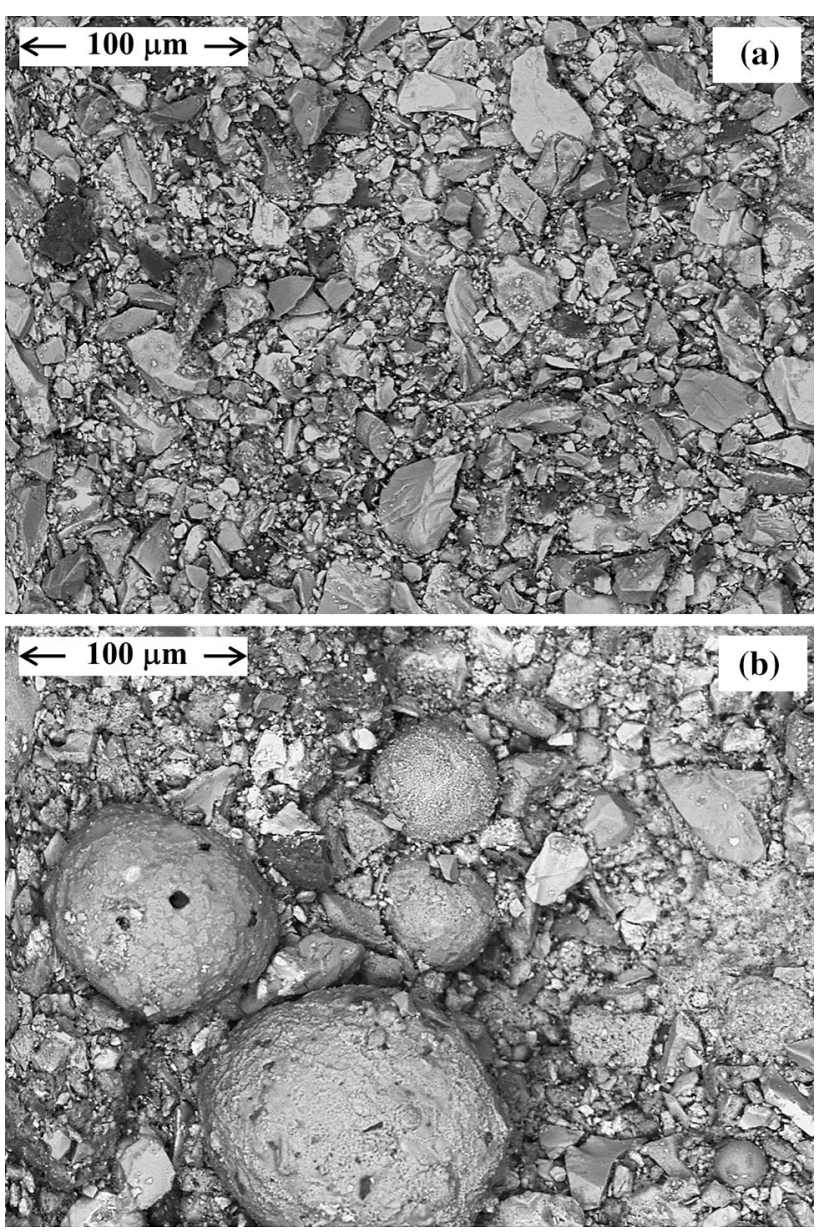

Fig. 18-SEM images of particles of size fraction $<45 \mu$ m oxidized under 70 pet $\mathrm{O}_{2}$ in the process gas; $(a)$ initial particles, (b) sample collected at $0.9 \mathrm{~m}$ from the lance tip.

melting occurred in those particles. Whereas some of them contained large cavities in their interior, others were ring-shaped or appeared to be large curved fragments originating from the explosion of an original particle. Some round particles showed numerous holes distributed throughout their volume, thus suggesting that fragmentation occurred in the population. Overall, the largest particles observed at $0.5,0.8$, and $0.9 \mathrm{~m}$ were typically massive and appeared as single entities, i.e., no evidence of particle aggregation was observed. Some of the apparent aggregates, such as those shown in the second row of the image corresponding to $0.3 \mathrm{~m}$, were likely artifacts of the scanning procedure followed by the QEMSCAN ${ }^{\circledR}$ unit, as no interaction among the particles is observed. It is of interest to note that the largest particles in the population mostly contained copper-iron sulfides, with minor amounts of iron oxides, copper-iron oxides, and iron spinel phase, i.e., they appeared to have reacted moderately even at the longest sampling location $(0.9 \mathrm{~m})$.

It is noted that the drastic transformations shown in Figure 19 were not observed in other sieved fractions tested in the experiments. It has been reported $^{[9,11,16,20,28,38]}$ that the finest particles in the concentrate cause a number of operational problems during flash smelting operation because they tend to form aggregates during feeding. Such aggregates are kept together by weak interparticle forces, such as van der Waals and electrostatic forces. ${ }^{[38]}$ In this work, the feeding of particles of the sieved fraction $<45 \mu \mathrm{m}$ faced such difficulties as well. However, the aggregates that possibly formed during feeding did not appear in the QEMSCAN® images. This was likely the result of sample preparation, as they were sonicated prior to being introduced into the QEMSCAN ${ }^{\circledR}$ unit. Therefore, if some aggregates were present in the sample, they were most likely disintegrated during sonication. On the other hand, the images shown in Figure 19 indicate a continuous growth of molten particles along the reactor. A possible explanation to this phenomenon is shown schematically in Figure 20. The process is initiated by the rapid melting of the finest particles in the feed before any significant reaction occurred in the particles. As the population of droplets traveled through the reactor, they collided and coalesced to form new droplets of larger sizes.

As far as the oxidation kinetics is concerned, the increase in droplet size is deleterious because it decreases the surface area available for the gas-liquid contact. Furthermore, the oxidation rate of a large reacting droplet is lower than that of a collection of small droplets with the same total volume. This hypothesis may explain the results obtained in this investigation, and the apparent low reactivity of fine particles reported by other authors in the past..$^{[9,16,22,23]}$ It also points out the relevance of the local density of the particle-gas suspension on the establishment of the reaction path followed by the particles during flash smelting. The larger the local density, the higher the probability of collisions and vice versa. On the other hand, such collisions will be effective as long they create new particles. ${ }^{[28]}$ Furthermore, the reaction path shown in Figure 20 will most likely occur with the finest particles in the feed, which are rapidly heated up by its surroundings and reach its melting point within a short distance from the reactor entrance.

Figure 21 shows a summary of the experimental data obtained in this work and those found in the literature for the oxidation of copper concentrate particles. For the preparation of this plot, only those publications that reported both the mean size and sulfur removal from the particles were selected. Here, the vertical axis represents the ratio between the mean size of the population measured at the sampling location $\langle x\rangle$ and the mean size of the population entering the reactor $\langle x\rangle_{0}$. The ratio $\langle x\rangle /\langle x\rangle_{0}$ is thus an indicator of the overall size changes experienced by the particles. Similarly, the horizontal axis represents their overall extent of oxidation in terms of the fraction of sulfur eliminated. Figure 21 is thus a correlation plot of two response variables along the trajectory of the particle population. For comparison purposes, the experimental values were plotted to separate the behavior of the finest particles in the feed from other sizes tested in each study. Figure 21 shows several features. First, most of the experimental data lay within area I which is located below the dashed 

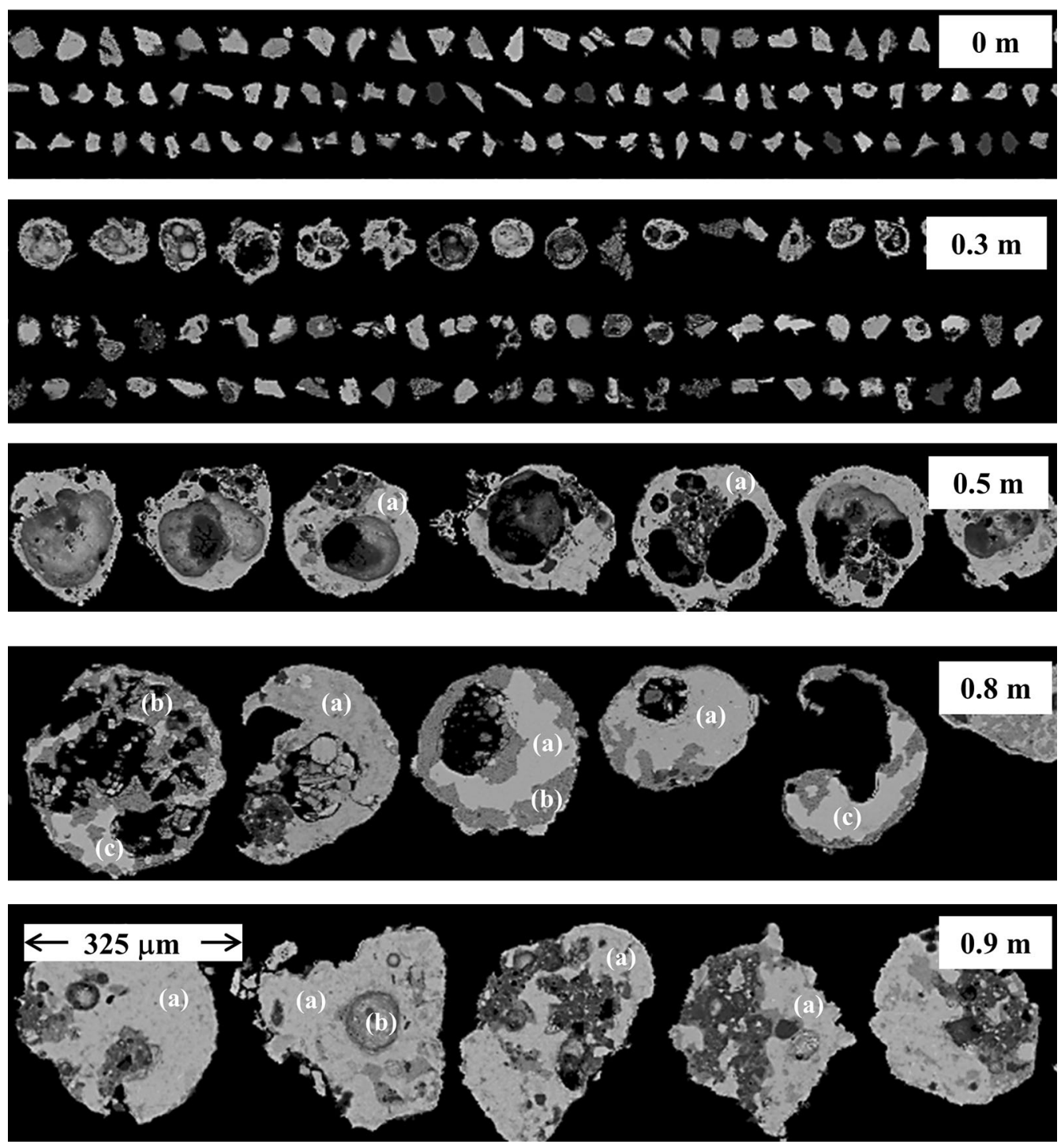

Fig. 19-QEMSCAN $®$ images of particles of size fraction $<45 \mu$ m oxidized under 70 pct $\mathrm{O}_{2}$ in the process gas; $(a)$ copper-iron sulfide, $(b)$ iron oxide, $(c)$ copper sulfide. Numbers on the right represent distance from the lance tip. The scale is the same for all images.

horizontal line defining the relationship: $\langle x\rangle /\langle x\rangle_{0}=1$. Therefore, a net decrease in the mean size of the population occurred as the particles underwent oxidation: $\langle x\rangle /\langle x\rangle_{0}<1$. It is noted that such data points are widely spread over the entire range of values of sulfur eliminated. This suggests that fragmentation occurred in those particles regardless of their stage of oxidation. As a result, both poorly and highly oxidized particles underwent similar extent of fragmentation. Such results are consistent with the reaction path shown in Figure 1. As the particles undergo oxidation, fragmentation occurs gradually throughout the population. It is noted that the data points located in area I were obtained under controlled laboratory conditions, in which the solid feed rate was typically kept at a very low level. Thus, it is expected that the particle-gas suspension was very dilute.

A second group of data in Figure 21 lay within area II which is located between the two curved, dashed lines in the central portion of the plot, and above the dashed horizontal line for which: $\langle x\rangle /\langle x\rangle_{0}=1$. In such experimental points, a net increase in the mean size of the population was observed as the particles underwent oxidation, i.e., $\langle x\rangle /\langle x\rangle_{0}>1$. Moreover, such data points suggest a strong correlation between the two output variables, i.e., an increase in the fraction of sulfur eliminated from the particles was associated with an increase in the mean size ratio and vice versa. It is emphasized that this group of data seems to be distributed within a limited range of values of sulfur eliminated, the maximum of which is about 0.6. This trend is consistent with the reaction path shown in Figure 20. Thus, in such experiments it is likely that collision and coalescence of droplets occurred simultaneously with the oxidation reactions. As partially reacted droplets continued to coalesce, the overall oxidation rate decreased due to the reduction of the available area for the gas-liquid contact. As a result, the 


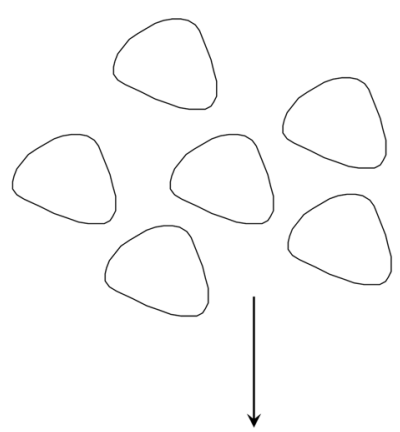

Original Sulfide Particles

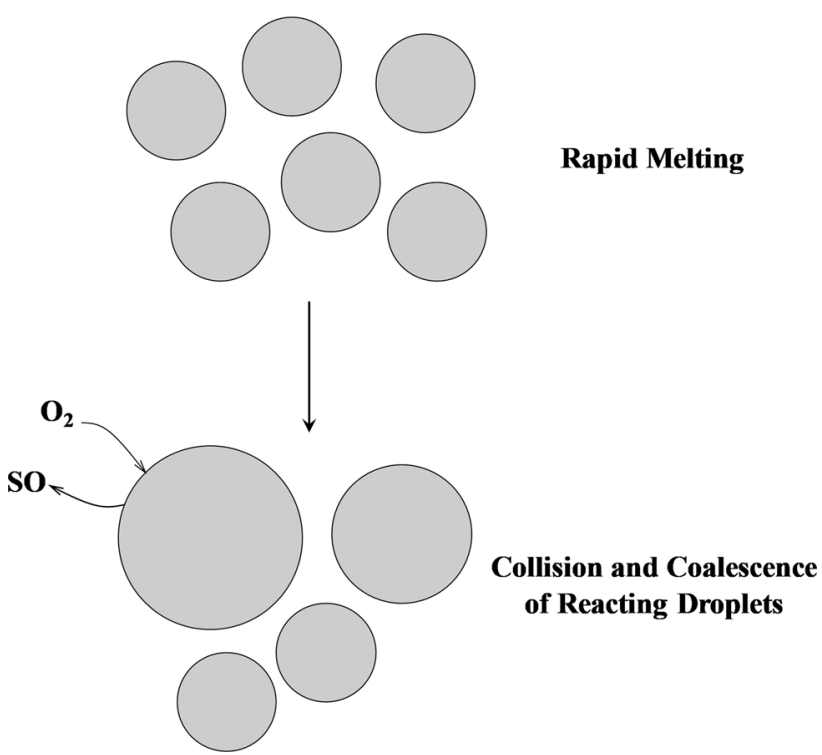

Fig. 20-Proposed reaction path of fine copper concentrate particles under conditions of high density of the particle-gas suspension.

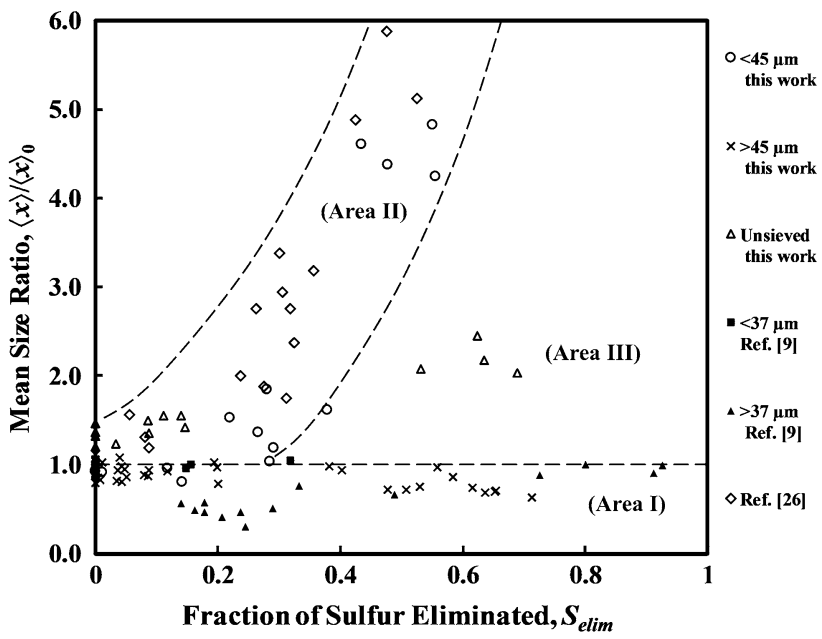

Fig. 21-Correlation of mean size ratio against fraction of sulfur eliminated from the particles for all the experimental conditions tested in this work. Data from Jorgensen ${ }^{[9]}$ and Kemori et al. ${ }^{[26]}$ are also shown for comparison.

rate of sulfur elimination also decreased. It is noted that data within area II corresponded to the pilot-scale experiments conducted by Kemori et al. ${ }^{[26]}$ and those obtained in this work with fraction $<45 \mu \mathrm{m}$. Some data points obtained in this work with the unsieved concentrate also followed this trend. As a comparison, the largest value of the ratio $\langle x\rangle /\langle x\rangle_{0}$ calculated from the data reported by Kemori et al. ${ }^{[26]}$ was about 5.9 , whereas that obtained in this work was 4.8. If the particles are assumed to be spherical, these values represent in average a 205 -fold and 110 -fold increase in particle volume, respectively, with respect to the feed. Such a large volume change is highly deleterious for the oxidation reactions, as they occur on the surface of the reacting droplets. On the other hand, the collision and coalescence of droplets decreases the number of particles within the dust range ( 0 to $20 \mu \mathrm{m}$ ) in the population. An example of this situation was shown in Figure 17 for the experiments conducted with fraction $<45 \mu \mathrm{m}$ and the unsieved concentrate.

Overall, the experimental data within area II suggest that the collision and coalescence of droplets took place with similar extent under both turbulent (Kemori et al. ${ }^{[26]}$ ) and laminar-flow conditions (this work). Such phenomena may occur provided the density of the particle-gas suspension is sufficiently high and the particles are small enough to become fully molten within the time spent in the reactor. In an industrial flash smelting facility, it is likely that the mechanisms shown in Figures 1 and 20 occur simultaneously depending on the history followed by the particles and the local conditions in the reactor. ${ }^{[27,39]}$ As current mathematical models of the flash smelting process ${ }^{[28,29,36,37,40-46]}$ typically assume a single reaction path followed by the particles, this issue represents an opportunity for their further improvement. Finally, few data points in Figure 21 lay within area III located at relatively large values of fraction of sulfur eliminated ( 0.5 to 0.7$)$ and size ratio values greater than unity. Such data points were obtained in experiments conducted in this work with the unsieved concentrate. Because the trends observed in areas I and II possibly represent the two extreme situations during particle oxidation, it is likely that such data points were the result of the combination of both reaction paths shown in Figures 1 and 20. This is because the unsieved concentrate showed a wide size distribution (Figure 7).

\section{CONCLUDING REMARKS}

The results of this investigation pointed out the effects of particle size, chemical composition, and the density of the particle-gas suspension on the reaction path followed by copper concentrate particles during oxidation under simulated flash smelting conditions. The finest particles $(<45 \mu \mathrm{m})$ underwent rapid melting followed by the collision and coalescence of reacting droplets during flight. They also increased their mean size and tended to decrease the amount of dust in the population during oxidation. In contrast, particles with sizes $>45 \mu \mathrm{m}$ followed a reaction path showing essentially no particle-particle interactions, and tended to either maintain or decrease their mean size upon oxidation. When size reduction was observed, dust was produced 
due to particle fragmentation. The oxidation behavior of the unsieved concentrate showed characteristics of both reaction paths.

Because the major sulfide species were highly liberated in the concentrate particles, the oxidation mostly occurred in free chalcopyrite and free pyrite particles. Their chemical transformations agreed well with previous studies reported in the literature, and were explained in terms of chemical reactions involving the vaporization of sulfur from chalcopyrite followed by oxidation to form matte, cuprospinel, and magnetite. The rate of oxidation was found to be dependent upon the reaction path followed by the particles in the reactor. In general, the collision and coalescence of droplets limited the removal of sulfur from the particles. A plot of the mean size ratio against the amount of sulfur eliminated proved to be useful to generalize the experimental data so far reported in the literature, and helped identify the major reaction paths followed by the particles under a variety of experimental conditions.

\section{ACKNOWLEDGMENTS}

Financial support for this investigation was provided by CONACYT (National Council of Science and Technology, México) under Project No. 104474, as well as a scholarship grant for graduate studies and a postdoctoral fellowship for one of the authors (VRPS). Special thanks are due to Dr. Komar Kawatra of Michigan Technological University for donating the electrical furnace for the oxidation tests. Acknowledgments are also due to Dr. Antelmo Robles-Vega ${ }^{\dagger}$ of Mexicana de Cobre, S.A., for providing the copper concentrate used in this study. VRPS thanks his current employer University of Talca, Chile, for providing support to publish this work.

\section{REFERENCES}

1. I.V. Kojo, A. Jokilaakso, and P. Hanniala: JOM, 2000, vol. 52, pp. $57-61$

2. H.Y. Sohn, S. Kang, and J. Chang: Min. Metall. Proc., 2005, vol. 22 , pp. $65-76$.

3. F.R. Jorgensen and E.R. Segnit: Proc. Australas. Inst. Min. Metall., 1977, vol. 261, pp. 39-46.

4. F.R. Jorgensen: Proc. Australas. Inst. Min. Metall., 1978, vol. 268 , pp. $47-55$

5. F.R. Jorgensen: Proc. Australas. Inst. Min. Metall., 1979, vol. 271, pp. 21-25.

6. F.R. Jorgensen: Proc. Australas. Inst. Min. Metall., 1980, vol. 276, pp. 41-47.

7. F.R. Jorgensen: Trans. Inst. Min. Metall. C, 1981, vol. 90, pp. C1C9.

8. F.R. Jorgensen: Trans. Ins. Min. Metall., 1981, vol. 90, pp. C10C16.

9. F.R. Jorgensen: Proc. Australas. Inst. Min. Metall., 1983, vol. 288, pp. $37-46$

10. Y.H. Kim and N.J. Themelis: in The Reinhardt Schuhmann International Symposium on Innovative Technology and Reactor Design in Extractive Metallurgy, D.R. Gaskell, J.P. Hager, J.E. Hoffman, and P.J. Mackey, eds., TMS, Warrendale, PA, 1986, pp. 349-69.
11. A.T. Jokilaakso, R.O. Suominen, P.A. Taskinen, and K.R. Lilius: Trans. Inst. Min. Metall. C, 1991, vol. 100, pp. C79-C90.

12. A.T. Jokilaakso, R.O. Suominen, P.A. Taskinen, and K.R. Lilius: Scand. J. Metall., 1989, vol. 18 (2), pp. 50-60.

13. A.T. Jokilaakso: Acta Poly. Scand. Chem. Tech. Ser., 1992, vol. 205, pp. 1-55.

14. A.T. Jokilaakso, P.A. Taskinen, R.O. Suominen, and K.R. Lilius: Scand. J. Metall., 1994, vol. 23 (2), pp. 54-61.

15. A.T. Jokilaakso, T. Ahokainen, O. Teppo, Y. Yang, and K. Lilius: Min. Proc. Ext. Metall. Rev., 1995, vol. 15, pp. 217-34.

16. A. Thomas, J.R. Grace, and I.V. Samarasekera: Can. Metall. Q., 2000, vol. 39, pp. 187-93.

17. F.R.A. Jorgensen and P.T.L. Koh: JOM, 2001, vol. 53 (5), pp. 16-20.

18. R.O. Suominen, A.T. Jokilaakso, P.A. Taskinen, and K.R. Lilius: Scand. J. Metall., 1991, vol. 20 (4), pp. 245-50.

19. R.O. Suominen, A.T. Jokilaakso, P.A. Taskinen, and K.R. Lilius: Scand. J. Metall., 1994, vol. 23 (1), pp. 30-36.

20. J.T. Yli-Penttilä, E.J. Peuraniemi, A. Jokilaakso, and K.M. Riihilahti: Min. Metall. Proc., 1998, vol. 15, pp. 41-47.

21. M. Perez-Tello, H.Y. Sohn, K. Marie, and A. Jokilaakso: Metall. Mater. Trans. B, 2001, vol. 32B, pp. 847-68.

22. R.D. Hagni, C.B. Vierrether, and H.Y. Sohn: Metall. Trans. B, 1988, vol. 19, pp. 719-29.

23. V. Stefanova and Y. Trifonov: Rus. J. Non-Ferr. Met., 2008, vol. 49, pp. 148-55.

24. J. Vaarno, J. Järvi, T. Ahokainen, T. Laurila, and P. Taskinen: Third International Conference on CFD in the Minerals and Process Industries, CSIRO, Melbourne, Australia. 2003. pp. 147-154.

25. T. Kimura, Y. Ojima, Y. Mori, and Y. Ishii: The Reinhardt Schuhmann International Symposium on Innovative Technology and Reactor Design in Extraction Metallurgy, D.R. Gaskell, J.P. Hager, J.E, Hoffman, and P.J. Mackey, eds., TMS, Warrendale, PA, 1986, pp. 403-418.

26. N. Kemori, Y. Ojima, and Y. Kondo: Flash Reaction Processes: Center for Pyrometallurgy Conference, D.G.C. Robertson, H.Y. Sohn, and N.J. Themelis, eds., University of Utah, Salt Lake City, UT, 1988, pp. 47-68.

27. N.J. Themelis, L. Wu, and Q. Jiao: Flash Reaction Processes: Center for Pyrometallurgy Conference, D.G.C. Robertson, H.Y. Sohn, and N.J. Themelis, eds., University of Utah, Salt Lake City, UT, 1988, pp. 263-285.

28. D.R. Higgins, N.B. Gray, and M.R. Davidson: Min. Eng., 2009, vol. 22, pp. 1251-65.

29. V.R. Parra-Sánchez, M. Pérez-Tello, C.A. Duarte-Ruiz, and H.Y. Sohn: Metall. Mater. Trans. B, 2014, vol. 45B, pp. 726-742.

30. V.R. Parra-Sánchez, M. Pérez-Tello, V.M. Sánchez-Corrales, A. Gómez-Álvarez, R. Parra-Figueroa, E. Balladares-Varela, and E. Araneda: Nickolas Themelis Symposium on Pyrometallurgy and Process Engineering/Copper 2013 International Conference, R. Bassa, R. Parra, A. Luraschi, and S. Demetrio, eds., IIMCh, Santiago, Chile., 2013, pp. 223-234.

31. V.R. Parra-Sánchez, M. Pérez-Tello, V.M. Sánchez-Corrales, R. Parra-Figueroa, and E. Balladares-Varela: Nickolas Themelis Symposium on Pyrometallurgy and Process Engineering/Copper 2013 International Conference, R. Bassa, R. Parra, A. Luraschi, and S. Demetrio, eds., IIMCh, Santiago, Chile, 2013, pp. 267-278.

32. E. Balladares, U. Kelm, S. Helle, R. Parra, and E. Araneda: DYNA, 2014, vol. 81, pp. 11-18.

33. H. Putz and K. Brandenburg: Match! version 3.4, Crystal Impact, Bonn, Germany, 2017.

34. A. Roine: HSC Chemistry for Windows version 5.11, Outokumpu Oy, Pori, Finland, 2002.

35. C.A. Duarte-Ruiz, M. Pérez-Tello, V.R. Parra-Sánchez, and H.Y. Sohn: Metall. Mater. Trans. B, 2016, vol. 47B, pp. 3115-25.

36. H.Y. Sohn and P.C. Chaubal: Metall. Mater. Trans. B, 1993, vol. 24B, pp. 975-85.

37. T. Ahokainen, A. Jokilaakso, J. Vaarno, and J. Järvi: International Conference in Mineral \& Metal Processing and Power Generation, CSIRO, Melbourne, Australia, 1997, pp. 213-21.

38. D.P. Debrincat, C.B. Solnordal, and J.S.J. Van Deventer: Powder Tech., 2008, vol. 182, pp. 388-97.

39. N. Kemori, W.T. Denholm, and H. Kurokawa: Metall. Trans. B, 1989, vol. 20 , pp. $327-36$

40. T. Ahokainen and A. Jokilaakso: Can. Metall. Q., 1998, vol. 37, pp. 275-83. 
41. T. Ahokainen, A. Jokilaakso, P. Taskinen, and M. Kytö: in Sohn International Symposium on Advanced Processing of Metals and Materials, F. Kongoli and R.G. Reddy, eds., The Minerals, Metals and Materials Society, San Diego, CA, 2006, pp. 529-43.

42. C.B. Solnordal, F.R. Jorgensen, P.T. Koh, and A. Hunt: Third International Conference on CFD in the Minerals and Process Industries, CSIRO, Melbourne, Australia, 2003, pp. 161-166.

43. C.B. Solnordal, F.R.A. Jorgensen, P.T.L. Koh, and A. Hunt: App. Math. Mod., 2006, vol. 30, pp. 1310-25.
44. C.B. Solnordal, F.R.A. Jorgensen, and A. Campbell: in Sohn International Symposium on Advanced Processing of Metals and Materials, F. Kongoli and R.G. Reddy, eds., The Minerals, Metals and Materials Society, San Diego, CA, 2006, pp. 687-701.

45. C.B. Solnordal, F.R.A. Jorgensen, and R. Russell: Seventh International Conference on CFD in the Minerals and Process Industries, CSIRO Australia, Melbourne, Australia, 2009.

46. M. Perez-Tello, H. Sohn, and P. Smith: Metall. Mat. Trans. B, 2001, vol. 32B, pp. 869-86. 